\title{
EL FINAL DEL GRAVETIENSE Y EL COMIENZO DEL SOLUTRENSE EN LA PENÍNSULA IBÉRICA. UN ESTADO DE LA CUESTIÓN ACERCA DE LA CRONOLOGÍA RADIOCARBÓNICA EN 2012
}

\section{The end of the Gravettian and the beginnings of the Solutrean in the Iberian Peninsula. An overview about the radiocabonical chronology in 2012}

\author{
Aitor Calvo ${ }^{1}$ y Alejandro Prieto ${ }^{1}$ \\ Recibido el 14 de marzo de 2013. Aceptado el 13 de septiembre de 2013
}

Resumen. El tránsito entre el final del Gravetiense y el inicio del Solutrense en la Península lbérica es, en términos geográficos, cronológicos y formales, una cuestión aún por resolver. Este trabajo tiene por objetivo arrojar la mayor cantidad de información, desde el punto de vista cronológico, sobre el tránsito entre ambos momentos crono-culturales a través de una perspectiva crítica. Para ello, hemos seleccionado las dataciones de esta cronología y asociado a ellas datos arqueológicos (industriales, principalmente) para, posteriormente, modelarlas a través del programa Oxcal 4.1.7. El cuadro cronológico generado, nos ha permitido definir a lo largo de toda la Península tanto los límites inferiores del tecno-complejo solutrense, como los límites superiores del Gravetiense y la relación entre ambas fases. Además, hemos reflexionado sobre el estado actual de la investigación en este periodo desde perspectivas cronológicas, teniendo en cuenta los avances en el método radiocarbónico.

Palabras clave: tránsito Gravetiense-Solutrense, Solutrense, Península lbérica, cronología radiocarbónica, marco cronológico.

Abstract. The transition between the end of the Gravettian and the beginning of the Solutrean in the Iberian Peninsula is, in geographical, chronological and formal aspects still full of uncertainties. The goal of this paper is clarify this problem with a critical perspective through a review of the available chronological evidence in the Iberian Peninsula. For this purpose, we have collected all the dates from this chronology and we have connected them with the archaeological data (mainly, industrial assemblages). This raw data has been modeled with the software $\mathrm{OxCal}$ 4.1.7. The chronological framework allows us to define the Solutrean lower limits and the upper limits of the Gravettian, and the relationship between both phases. In addition, we considered the general overview of this period from a chronological perspective, keeping in mind the developments made in the radiocarbon methodology.

Keywords: Gravetian-solutrean transition, Solutrean, Iberian Peninsula, radiocarbon chronology, chronological framework.

(') Área de Prehistoria. Dpto. de Geografía, Prehistoria y Arqueología. Universidad del País Vasco / Euskal Herriko Unibertsitatea (EHU/UPV). Calle Francisco Tomás y Valientes/n. E-01006 Vitoria-Gasteiz. aitor_calvo@ehu.es ; alejandro.prieto@ehu.es 


\section{INTRODUCCIÓN}

El origen y difusión de las industrias solutrenses, en términos tanto cronológicos como geográficos, ha sido una de las cuestiones más atendidas y controvertidas dentro de la historiografía del Paleolítico superior europeo (vid. e. g. Laplace 1962; Smith 1966; Straus 1983; de la Rasilla y Llana 1995; Zilhão et al. 1999; Renard 2010 y 2011). Dentro de esta discusión, la Península Ibérica ha jugado un papel importante como uno de sus escenarios principales, especialmente en relación a las teorías que defendian una vinculación filogenética entre las industrias aterienses norteafricanas y las solutrenses europeas, ideas reevaluadas recientemente (Tiffagom 2005 y 2006; Alcaraz Castaño 2007). El resto de hipótesis propuestas hasta el momento, de entre las cuales prepondera actualmente la del origen Gravetiense del utillaje foliáceo Solutrense (con un posible germen en las puntas de La Font-Robert), no han zanjado definitivamente este debate. Esta última propuesta, válida como explicación del origen técnico del Solutrense, pone en estrecha relación ambos tecno-complejos, haciéndolos, en nuestra opinión, indisolubles a la hora de plantear un estudio de estas características. Por otro lado, el último tramo cronológico del Gravetiense, convulso desde el punto de vista climático y ambiental, ha sido una problemática menos atendida en la historiografía. A este respecto, encontramos en la bibliografía una extensa variedad terminológica en la definición de los distintos conjuntos industriales de este lapso, tales como Auriñaciense V/Auriñaciense tardío, Protomagdaleniense/Perigordiense VII o Gravetiense final sensu lato, entre otros (Bosselin y Djindjian 1997). Esta miscelánea es un claro reflejo de una realidad arqueológica, aún, poco comprendida.

En lo cronológico, se viene asumiendo, grosso modo, que las últimas industrias asignables al Gravetiense de Europa occidental se documentan, dependiendo de las regiones, en torno al 22000-21000 BP, fechas en las que también se identifican niveles adscritos al Protosolutrense. A continuación, entre el 21000 y el 20000 BP, daría comienzo el tecno-complejo solutrense en Francia y la Península Ibérica (Zilhão y Aubry 1995; Djindjian et al. 1999; Zilhão et al. 1999). La realidad de este periodo en la Península es, como veremos en las páginas siguientes, mucha más compleja, con ritmos de evolución bien distintos a lo largo y ancho de su geografía.

El trabajo que a continuación presentamos está basado en la selección, calibración y valoración crítica de las dataciones radiocarbónicas disponibles en la bibliografía y en el análisis de su contexto arqueológico, todo ello con el objetivo de profundizar en el conocimiento de este momento transicional clave del Paleolítico superior europeo.

\section{MÉTODOS Y MATERIALES}

Hemos organizado este apartado en función de las distintas fases de análisis seguidas para el desarrollo de este trabajo. Estas se organizan en 5 epígrafes diferenciados: (1) Definición del marco geográfico de estudio; (2) Recogida de datos y selección de dataciones; (3) Contextualización de las dataciones; (4) Procesado de las dataciones; y (5) Materiales.

\subsection{Definición del marco geográfico de estudio}

El marco geográfico general seleccionado para este estudio se ciñe a la Península Ibérica. Debido a su amplitud y heterogeneidad arqueológica, la hemos dividido en tres zonas principales de análisis (Fig. 1). Éstas se justifican en virtud a una identidad propia, bien en lo arqueológico-gracias a la relativa uniformidad material documentada en cada una de ellas-, bien en lo geográfico -debido a su circunscripción a territorios bien diferenciados-. Las tres áreas constituidas son las siguientes:

1. Área cantábrica: Esta zona se extiende por el norte de la Península lbérica y comprende las actuales comunidades autónomas de Asturias, Cantabria y País Vasco.

2. Área mediterránea: es la región que abarca el Litoral mediterráneo peninsular, desde el cabo de Rosas hasta el estrecho de Gibraltar, y que profundiza en el interior por el valle medio del Ebro.

3. Área atlántica: limitada en la región centro-sur de Portugal.

\subsection{Recogida de datos y selección de dataciones}

Para la realización de este trabajo hemos seguido una metodología basada en la pesquisa bibliográfica de todas las dataciones que puedan solucionar la problemática a la que nos enfrentamos. Además, hemos recogido la información referente a: (1) Información geográfica de los yacimientos datados; (2) Información estratigráfica y medioambiental de los mismos; y (3) Información sobre el contexto material de las dataciones, especialmente de las industrias lítica y ósea.

Una vez obtenidas las dataciones, hemos decidido realizar una serie de acotaciones que permitan obtener una mayor información de los datos:

1. Selección metodológica de las dataciones, tomando por precisión, potencialidad y estandarización, las radiocarbónicas

2. Afinamiento cronológico del periodo a fin de centrar nuestro sujeto de estudio, el tránsito Grave- 


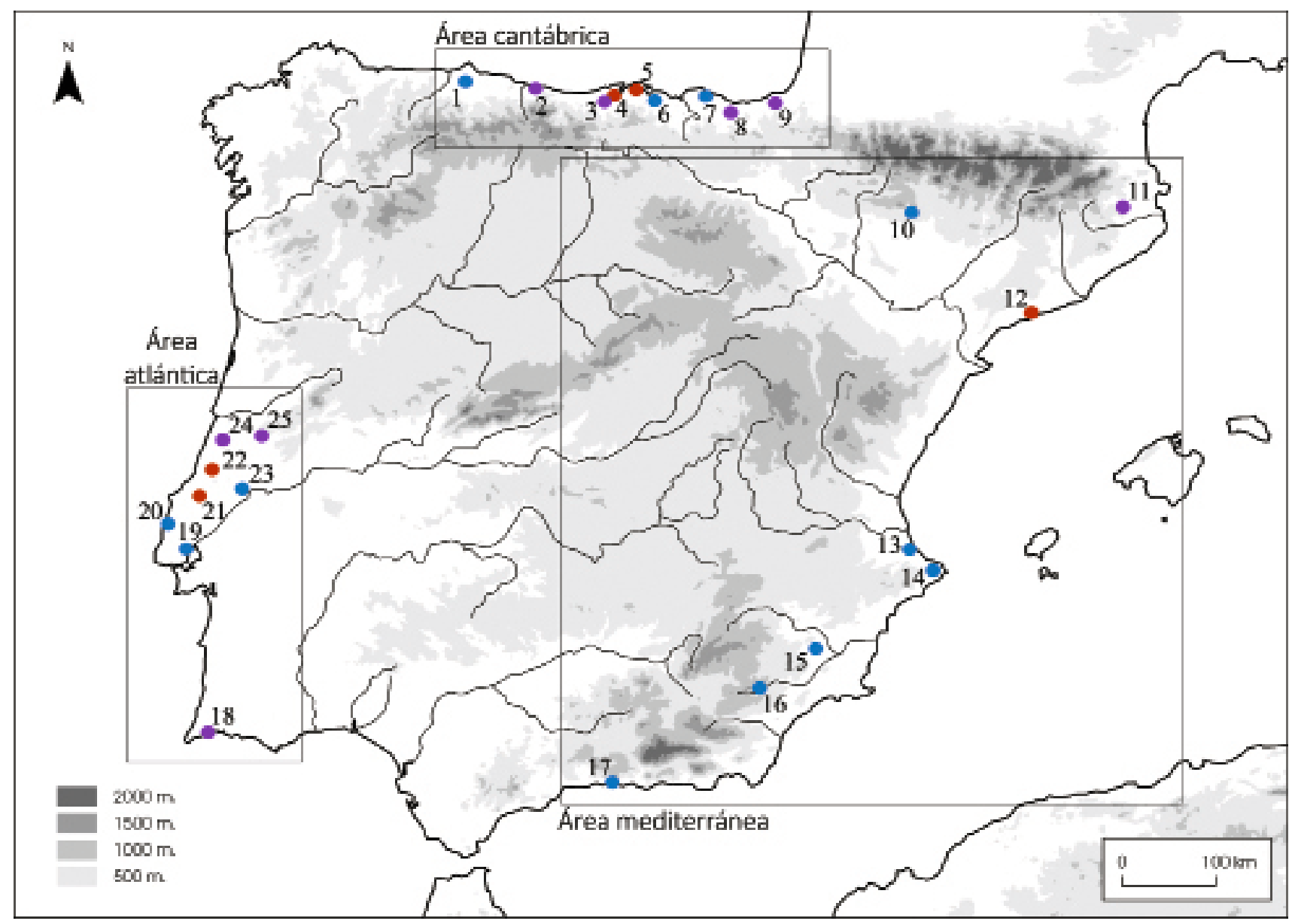

A Figura 1. Área cantábrica: 1-Las Caldas (Oviedo, Asturias) S; 2-La Riera y Cueto de la Mina (Posada de Llanes, Asturias) G y S; 3- Hornos de la Peña (San Felices de Buelna, Cantabria) G y S; 4-Cueva Morin (Villaescusa, Cantabria) G; 5-La Garma (Omoño, Cantabria) G; 6-El Mirón (Ramales de la Victoria, Cantabria) S; 7-Antoliñako Koba (Gauteguiz-Arteaga, Vizcaya) S; 8- Amalda (Zestoa, Gipuzkoa) G y S; 9-Aitzbitarte IV y Aitzbitarte III (Errentería, Gipuzkoa) S y G. Área mediterránea: 10- Chaves (Casbas de Huesca, Huesca) S; 11-L'Arbreda (Serinyà, Girona) G y S y Roc de la Melca (Sant Aniol de Finestres, Girona) G; 12- Balma de la Griera (Calafell, Tarragona) G; 13- Les Mallaetes (Bárig, Valencia) S y Parpalló (Gandía, Valencia) S; 14-Les Cendres (Teulada, Alicante) S; 15-La Boja S y Finca de Doña Martina S (Mula, Murcia); 16-Ambrosio (Vélez-Blanco, Almería); 17-Nerja (Nerja, Málaga); Área atlántica: 18-Vale Boi (Vila do Bispo, Algarve) G y S; 19-Salemas (Ponte de Lousa, Loures) S; 20-Vale Almoinha (Cambelas, Torres Vedras) S; 21 - Terra do Manuel (Rio Maior) G; 22-Lapa do Anecrial (Porto de Mós, Leiria) G; 23-Caldeirão (Tomar, Santarém), S; 24- Lagar Velho (Santa Eufémia, Leiria) G y S; 25- Buraca Grande y Buraca Escura (Redinha, Pombal) G y S.

tiense-Solutrense, que hemos delimitado entre el 22500 BP y el 17500 BP sin calibrar.

3. Eliminación de las dataciones que no responden a la problemática propuesta, aun perteneciendo al rango cronológico acotado o compartiendo la naturaleza radiocarbónica del método. No han pasado este filtro las dataciones que no tienen un nivel arqueológico claro y definido o las que los niveles datados no tienen componente humano (niveles arqueológicamente estériles, niveles en yacimientos paleontológicos, dataciones relativas al arte rupestre fuera de contexto...).

4. Exclusión de las dataciones que no consideramos suficientemente precisas para la resolución de la problemática propuesta. Por ello, hemos eliminado aquellas dataciones con rangos de desviación típica superiores a 500 años. Este es un lapso que aunque arbitrariamente escogido, creemos responde a las características de precisión necesarias que se ajustan a nuestro estudio.

\subsection{Contextualización de las dataciones}

Respecto a las dataciones obtenidas, las consideramos como un elemento más que nos permite apreciar de forma más clara la perspectiva del tránsito entre estas dos etapas. Buscamos comprender las dataciones no como un elemento de fiabilidad absoluta, si no como un elemento en contexto. Este hace referencia a: (1) un contexto arqueológico, definido por las características arqueológicas que se asocian a cada datación; y (2) un contexto técnico que define las características del proceso por el que la muestra ha sido tomada hasta la obtención de una edad isotópica. 
Recurrimos al contexto arqueológico y, dentro de este, a la caracterización industrial lítica para clasificar las dataciones en dos grandes grupos. El primer grupo es el Presolutrense/Gravetiense, en el que hemos incluido todas aquellas dataciones de niveles que, dentro de la cronología propuesta, han sido adscritos al Gravetiense o, teniendo otra adscripción crono-cultural, carecen de caracteres propios del Solutrense (morfotipos foliáceos). Estos niveles han sido definidos en la bibliografía con diferente nomenclatura (Perigordiense final, Perigordiense VII/Protomagdaleniense/ Auriñaciense V, Gravetiense final, Protosolutrense). El término presolutrense, aun usado anteriormente (Jordá 1954), en el marco de este trabajo simplemente intenta aunar esta variedad terminológica. El segundo grupo es el Solutrense, claramente establecido por la bibliografía (Leroi-Gourhan 1988: 985; Straus 2001). En aquellos casos en los que la bibliografía no plantea una clara adscripción industrial, hemos utilizado como elemento discriminante entre ambos grupos los mencionados caracteres clásicos asociados al Solutrense.

Respecto al contexto técnico, hemos revisado la metodología subyacente en la realización del cuenteo radioactivo del $\mathrm{C} 14$, diferenciando así qué dataciones han sido realizadas a través de $\mathrm{C} 14$ convencional y cuáles han sido realizadas a través del AMS, una técnica, a priori, menos destructiva y más precisa (Linick et al. 1989). Las dataciones que han sido efectuadas a través de la técnica del AMS han sido valoradas de una forma positiva en este estudio y han permitido otorgar mayor rango de fiabilidad a las conclusiones que de ellas se derivan. Por otro lado, nos hubiera gustado tener en cuenta otro tipo de caracteres o factores, como son el tipo de pretratamiento de muestras empleado o la contrastación de ratios isotópicos que reflejen la idoneidad de unas muestras con respecto a otras. Este factor, por falta de información, no hemos sido capaces de recoger sistemáticamente y por tanto de valorar.

\subsection{Procesado de las dataciones}

Para procesar estos datos, hemos utilizado el programa 0xCal, versión 4.1 (Bronk Ramsey 2009a), desarrollado por el ORAU, que además de calibrar las dataciones introducidas con la más novedosa y precisa curva de calibración radiocarbónica, INTCAL09 (Reimer et al. 2009), permite la utilización de la estadística bayesiana con el fin de modelar estas dataciones junto con información derivada del contexto que rodea a las propias dataciones. Esto nos ha permitido, por un lado, relacionar la mayor cantidad de información posible $y$, por otro, juzgar a través del análisis de concordancia (Agreement, A) los esquemas planteados para cada fase sin que estén atados a los rígidos modelos preestablecidos (Bronk Ramsey 2009b). Además, posibilita la representación gráfica de las dataciones y los esquemas planteados en una línea temporal.
Para el procesado de las dataciones en el software se han diferenciado las tres áreas ya citadas, generando tres modelos. Dentro de estos, las dataciones han sido introducidas en dos las dos fases (articuladas como secuencias) previamente descritas, una Presolutrense y otra Solutrense. Debido a las limitaciones impuestas por el desigual estado de la investigación y el amplio rango geográfico manejado, hemos considerado que los constreñimientos de estas fases $y$ su relación sea lo más baja posible, sin introducir más condicionantes de los ya enunciados y descartando así el análisis de Outliers. De las fases, hemos generado rangos modelados para sus límites (Boundary), que han servido para el establecimiento del final de la fase presolutrense y el inicio de la fase solutrense.

\subsection{Materiales}

Los materiales utilizados en este trabajo se componen de 80 dataciones radiocarbónicas tomadas de 58 niveles arqueológicos. Esta selección, creemos es representativa para el presente trabajo y es el producto de la pesquisa bibliográfica y filtrado de dataciones. Del total de dataciones, 34 corresponden al área cantábrica, 19 al área mediterránea y 27 al área atlántica. De todas ellas, 37 están obtenidas por C14 Convencional y 43 por la técnica del AMS. Respecto a las fases ya comentadas 27 dataciones corresponden a niveles de la fase presolutrense/gravetiense y 53 a la fase Solutrense. Todas las dataciones se encuentran recogidas en varias tablas en los anexos de este trabajo (Tabs. 1, 2 y 3 ).

\section{RESULTADOS}

En el siguiente apartado se exponen los resultados obtenidos, organizados por áreas geográficas. Todas las fechas aquí recogidas son aquellas que han cumplido los requisitos expuestos en la sección previa.

\section{1 Área cantábrica}

El área cantábrica, la primera de las tres consideradas, resulta la más prolífica en cuanto a número de yacimientos (14), niveles arqueológicos datados (24) y fechas radiocarbónicas (34) disponibles para ambos momentos crono-culturales (Tabla 1). A pesar de la descompensación que genera la serie de la cueva de Las Caldas, de la cual provienen siete de los 15 niveles valorados para la fase Solutrense, el volumen general de fechas obtenido para los dos periodos es similar (15 gravetienses y 19 solutrenses), dando como resultado una secuencia cronológica de cierto equilibrio. Geográficamente, ambas fases se encuentran relativamente bien representadas a lo largo de la cornisa cantábrica, a excepción de Galicia, para la cual no conta- 


\begin{tabular}{|c|c|c|c|c|c|c|c|c|c|c|}
\hline AR & YACIMIENTO & NIVEL & COD. LAB. & MT & MTD & FECHA BP & CALIB.BP $2 \sigma$ & MODEL.BP $2 \sigma$ & $A D$ & REFERENCIA BIBLIOGRÁFICA \\
\hline C & LA GARMA & $\mathrm{E}$ & TO-11697 & $\mathrm{H}$ & c & $22200 \pm 170$ & 27587-26150 & 27405-25966 & G & Arias et al. 2003 \\
\hline C & LA RIERA & 1 & BM-1739R & $\mathrm{H}$ & C & $21100 \pm 420$ & $26603-24210$ & $26202-24140$ & G & Straus et al. 1986 \\
\hline $\mathrm{C}$ & HORNOS DELA PEÑA & D & BM-1883R & $\mathrm{H}$ & C & $20930 \pm 370$ & $26075-24120$ & $25923-24017$ & G & Bowman et al. 1990 \\
\hline C & LA RIERA & 1 & Ly-1783 & $\mathrm{H}$ & C & $20360 \pm 450$ & $25634-23290$ & $25512-23218$ & G & Straus et al. 1986 \\
\hline C & AITZBITARTE III & III-6 & Ua-11147 & $?$ & AMS & $20405 \pm 130$ & 24799-23915 & 24781-23909 & G & Altuna et al. 2011 \\
\hline C & AITZBITARTE III & III-7 & Ua-11149 & $?$ & AMS & $20290 \pm 260$ & 24946-23604 & $24906-23550$ & G & Altuna et al. 2011 \\
\hline C & MORÍN & $5 a$ & Si-953 & C & C & $20124 \pm 340$ & 24975-23275 & 24957-23218 & G & González Echegaray y Freeman, 1978 \\
\hline $\mathrm{C}$ & AITZBITARTE III & III-3 & Ua-37959 & $?$ & AMS & $19765 \pm 220$ & $24304-22727$ & $24269-22702$ & $\mathrm{G}$ & Altuna et al. 2011 \\
\hline C & AITZBITARTE III & III-5 & Ua-18463 & $?$ & AMS & $19715 \pm 235$ & $24238-22676$ & $24184-22669$ & G & Altuna et al. 2011 \\
\hline C & LA RIERA & 1 & UCR-1270A & $\mathrm{H}$ & $\mathrm{C}$ & $19620 \pm 390$ & 24371-22447 & $24313-22426$ & G & Straus y Clark 1986 \\
\hline C & AITZBITARTE III & III-4 & Ua-37960 & $?$ & AMS & $19400 \pm 210$ & $23725-22491$ & $23700-22480$ & G & Altuna et al. 2011 \\
\hline C & AITZBITARTE III & III-8 & Ua-24964 & $?$ & AMS & $19230 \pm 200$ & $23490-22389$ & 23473-22383 & G & Altuna et al. 2011 \\
\hline $\mathrm{C}$ & AMALDA & $\mathrm{V}$ & $\mathrm{I}-11372$ & $\mathrm{H}$ & $\mathrm{C}$ & $19000 \pm 340$ & $23649-21820$ & $23609-21987$ & G & Altuna et al. 1984 \\
\hline $\mathrm{C}$ & AITZBITARTE III & III-7 & Ua-11150 & $?$ & AMS & $18400 \pm 215$ & 22414-21451 & $22487-21545$ & G & Altuna et al. 2011 \\
\hline C & AMALDA & $\mathrm{V}$ & I-11663 & $\mathrm{H}$ & C & $17880 \pm 390$ & 22291-20354 & 22907-21202 & G & Altuna et al. 1984 \\
\hline C & LAS CALDAS & 15 & Ua-15318 & C & AMS & $20250 \pm 235$ & $24855-23577$ & $24262-23294$ & $\mathrm{~S}$ & Corchón 1999 \\
\hline C & HORNOS DE LA PEÑA & C & BM-1882R & $\mathrm{H}$ & $\mathrm{C}$ & $20180 \pm 310$ & 24925-23395 & $24273-23086$ & $S$ & Bowman et al. 1990 \\
\hline C & LA RIERA & 10 & Gak-6447 & $\mathrm{C}$ & $\mathrm{C}$ & $19820 \pm 390$ & $24672-22530$ & $24108-22600$ & $S$ & Straus y Clark 1986 \\
\hline C & LAS CALDAS & 16 & Ly-2428 & $\mathrm{H}$ & $\mathrm{C}$ & $19510 \pm 330$ & $24133-22426$ & $23906-22478$ & $\mathrm{~S}$ & Evin et al. 1983 \\
\hline C & LAS CALDAS & 12 & Ly-2426 & $\mathrm{H}$ & C & $19480 \pm 260$ & $23900-22483$ & $23837-22537$ & $S$ & Evin et al. 1983 \\
\hline C & LAS CALDAS & 9 & Ly-2424 & $\mathrm{H}$ & C & $19390 \pm 260$ & $23807-22436$ & $23765-22474$ & $\mathrm{~S}$ & Evin et al. 1983 \\
\hline C & ANTOLIÑAKO KOBA & Lmc & GrN-23785 & $\mathrm{H}$ & AMS & $19280 \pm 120$ & $23435-22515$ & $23446-22536$ & $S$ & Aguirre 2003 \\
\hline C & EL MIRÓN & 127 & UG-7216 & $\mathrm{C}$ & AMS & $19230 \pm 50$ & $23356-22546$ & $23365-22560$ & $S$ & Straus et al. 2011 \\
\hline C & CUETO DE LA MINA & $\mathrm{Vb} / \mathrm{E}$ & Ua-3586 & $\mathrm{H}$ & AMS & $19110 \pm 205$ & 23399-22315 & $23420-22338$ & $S$ & Hoyos y de la Rasilla ,1994 \\
\hline C & LAS CALDAS & 12 & Ly-2425 & $\mathrm{H}$ & $\mathrm{C}$ & $19030 \pm 320$ & $23673-22015$ & $23627-22115$ & $\mathrm{~S}$ & Evin et al.1983 \\
\hline C & LAS CALDAS & 18 & Ly-2429 & $\mathrm{H}$ & C & $19000 \pm 280$ & $23498-22070$ & $23497-22143$ & $\mathrm{~S}$ & Evin et al.1983 \\
\hline C & EL MIRÓN & 125 & GX-24470 & $\mathrm{H}$ & C & $18980 \pm 360$ & 23644-21709 & $23702-21952$ & $S$ & Straus y González 2003 \\
\hline C & EL MIRÓN & 126 & GX-24471 & $\mathrm{H}$ & $\mathrm{C}$ & $18950 \pm 350$ & $23542-21638$ & $23650-21870$ & $S$ & Straus y González 2003 \\
\hline C & EL MIRÓN & 121 & GX-32655 & $\mathrm{H}$ & $\mathrm{C}$ & $18390 \pm 300$ & $22653-21213$ & $23195-21325$ & $S$ & Straus et al. 2011 \\
\hline C & LAS CALDAS & 11 & Ua-15316 & $\mathrm{H}$ & AMS & $18305 \pm 295$ & $22542-21638$ & $22890-21291$ & $S$ & Corchón 1999 \\
\hline C & LAS CALDAS & 7 & Ly-2423 & $\mathrm{H}$ & $\mathrm{C}$ & $18250 \pm 300$ & $22570-21210$ & $22468-21367$ & $S$ & Evin et al. 1983 \\
\hline C & AITZBITARTE IV & $\mathrm{VII}$ & GrN-5993 & $\mathrm{H}$ & C & $17950 \pm 100$ & $22435-21307$ & 21896-21135 & $S$ & Altuna,1972 \\
\hline C & LAS CALDAS & 9 & Ua-15315 & $\mathrm{H}$ & AMS & $17945 \pm 370$ & 21806-21077 & 22468-20617 & $S$ & Corchón 1999 \\
\hline C & AMALDA & IV & I-11355 & $\mathrm{H}$ & C & $17580 \pm 440$ & $22310-20430$ & $22396-20428$ & $S$ & Altuna et al. 1984 \\
\hline
\end{tabular}

- TABla 1. Tabla de las dataciones seleccionadas para este estudio (1). Se hace referencia al área a la que pertenecen (AR), el yacimiento, el nivel, el código de laboratorio (COD. LAB), el material datado (MT: H para hueso, C para carbón y Co para concha) la metodología utilizada (MTD: AMS o C para C14 Convencional), datación BP (FECHA BP), datación calibrada (CALIB. BP 2б), modelación de la datación a $2 \sigma$ (MODEL.BP 2 $\sigma$ ), Adscripción cultural (AD: G para Presolutrense/Gravetiense y S para Solutrense) y la Referencia bibliográfica.

mos aún con dataciones relativas a nuestro marco cronológico de estudio.

Este equilibrio no puede ser, sin embargo, extrapolado al ámbito metodológico, en el que hemos observado una predominancia de dataciones obtenidas por $\mathrm{C} 14$ convencional con respecto a las de AMS (21 por 13 respectivamente). Esto se hace más patente en el conjunto de fechas solutrenses, con solo seis obtenidas por este último método, en contraposición a las 13 de C14 convencional. La gran mayoría de estas últimas provienen de yacimientos datados entre las décadas de los '70 y los '90 (Morín, Hornos de la Peña, La Riera y Las Caldas), cuando aún no estaba extendido el uso de la técnica del AMS. Esta descompensación metodológica tiene importantes implicaciones en la fiabilidad y precisión de las fechas radiocarbónicas, complicando la lectura de las secuencias cronológicas calibradas y las conclusiones derivadas de estas.
La secuencia de fechas calibradas y modeladas del área cantábrica se muestra en la Fig. 2.

Por un lado, el agreement o concordancia general de la secuencia (86) es muy aceptable, lo cual refleja una gran coherencia interna de la serie. Individualmente, la mayoría de dataciones tienen valores altos $(A \approx 100)$. Como contrapunto, nos encontramos con dos fechas con concordancias problemáticas en dos de los extremos de ambas fases: la del nivel V de Amalda (I-11663) para la gravetiense y la del nivel 15 de Las Caldas (Ua-15318) para la solutrense. Sus valores de agreement (68 y 58 respectivamente) aconsejan tomarlas en consideración con ciertas reservas.

Dejando a un lado las valoraciones individuales, los elementos que más nos interesan dentro de la secuencia son los dos boundaries o rangos modelados generados, tanto el relativo al final de las industrias presolutrenses/gravetienses 


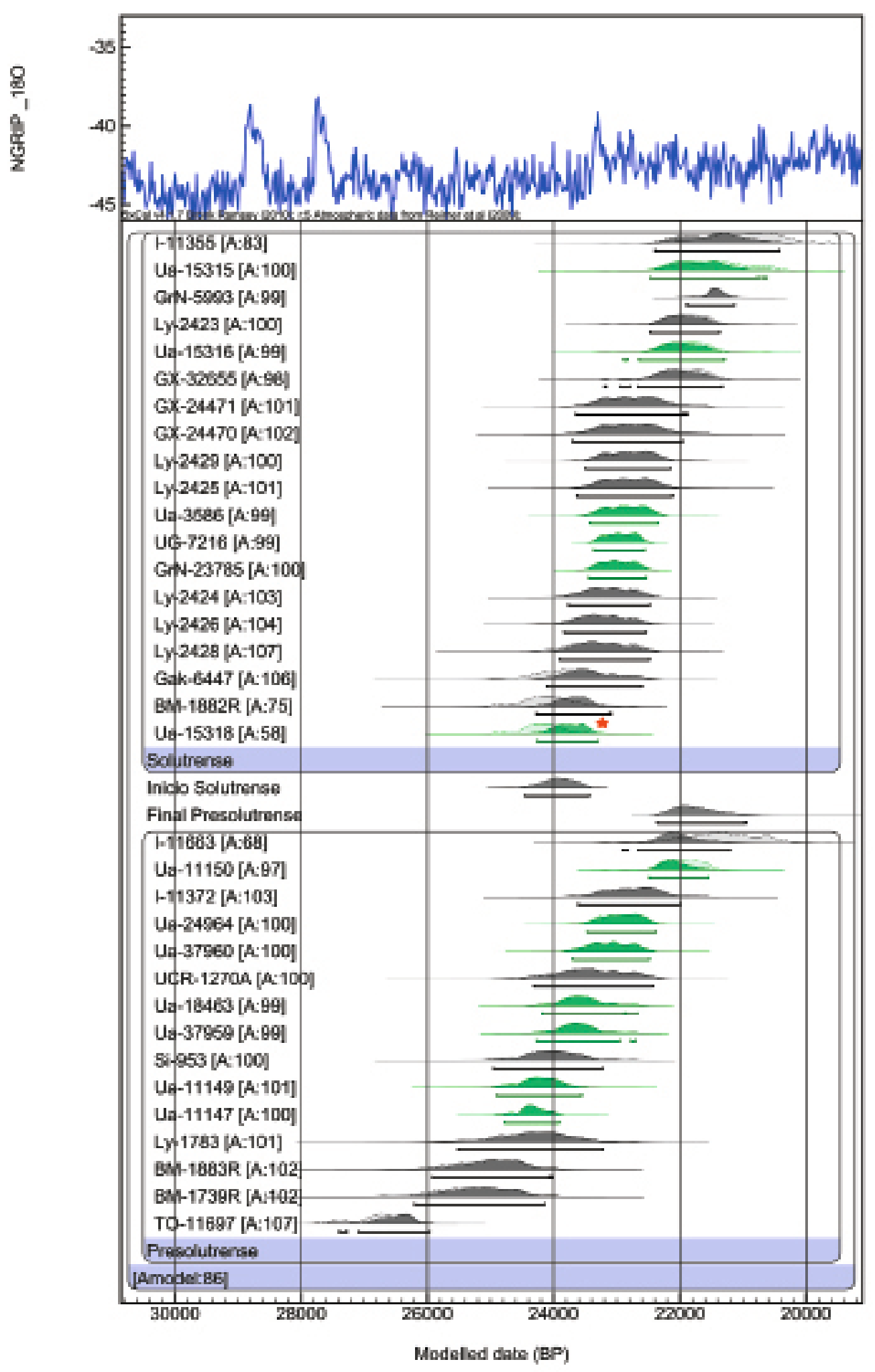

A FiguRA 2. Secuencia cronológica calibrada y modelada del área cantábrica. Las dataciones por AMS están coloreadas en verde. Las zonas de coloración más clara corresponden a los rangos calibrados y las más oscuras corresponden a los rangos modelados. El asterisco hace referencia a que la datación guarda un bajo índice de Agreement.

como el referente al inicio del utillaje foliáceo solutrense. El rango modelado del final del tecno-complejo presolutrense/ gravetiense obtenido es el que se observa en la Fig. 3.
Este primer rango modelado oscila entre el 22363 y el 20965 cal BP (2 $\sigma)$, situándose la media en un valor de 21740 \pm 369 cal BP y la mediana en 21796 cal BP. Este límite viene 


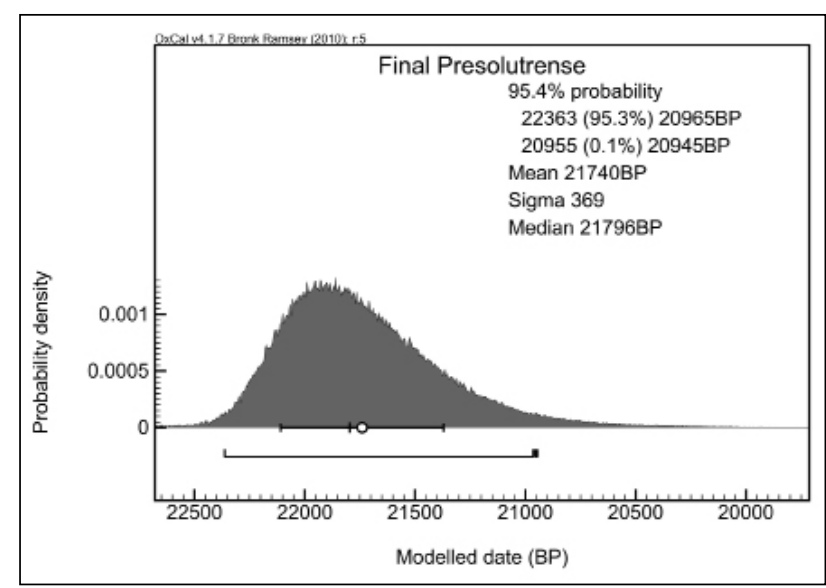

A Figura 3. Detalle del rango modelado del final del tecno-complejo Gravetiense/Presolutrense en el área cantábrica.

marcado, principalmente, por las fechas de los niveles $\mathrm{V}$ de Amalda y varias de las obtenidas en los niveles 1 de La Riera y III de Aitzbitarte III, todas ellas (salvo, como hemos comentado, la I-11663 del nivel V de Amalda) con valores de concordancia altos. Sin embargo, la filiación cultural de estos niveles resulta problemática y controvertida, por lo que la significación arqueológica de este rango resulta complicada de definir. En primer lugar, nos encontramos con el nivel $V$ de Amalda, atribuido originariamente al Perigordiense VII/Protomagdaleniense (Baldeón 1990) y algo más recientemente al Gravetiense final sensu lato (Arrizabalaga 1995). A pesar de que ambos autores describen en él un número testimonial de útiles de retoque plano, ninguno de ellos se corresponde con elementos foliáceos de clara adscripción Solutrense. Por otro lado, la presencia -numéricamente también escasa- de buriles de Noailles parece vincular este horizonte, aunque no de forma decisiva (A. Arrizabalaga comunicación personal) con el Gravetiense del nivel VI infrayacente, rico en este tipo de artefactos. La adscripción de este nivel $\mathrm{V}$ a un momento muy terminal del Gravetiense nos parece, de este modo, la más plausible.

El nivel 1 de La Riera, por su parte, carece de adscripción crono-cultural precisa (Straus et al. 1986). Vinculado al Auriñaciense $\mathrm{V}$ y comparado tipológicamente con el nivel 9 de Rascaño, este nivel se caracteriza por una industria de grandes láminas retocadas de "estilo auriñaciense", estando en ella totalmente ausente cualquier forma típica del Gravetiense o Solutrense. Así mismo, Straus y Clark (1986) la consideran una fecha problemática, por estar, en su opinión, claramente rejuvenecida. A estas dudas sobre la fiabilidad de la datación se une su ambigüedad tecno-tipológica, lo que hace de este un nivel poco informativo para el propósito de este trabajo.

Ciertos problemas de fiabilidad también se derivan de la serie de dataciones del nivel III de Aitzbitarte III (Altuna et al. 2011:36-38). La máxima horquilla cronológica de las siete fechas obtenidas es de más de 4.500 años, entre el
22875 BP y el 18185 BP, lo cual pone en duda la validez de algunas de ellas. Aun así, prácticamente todas son posteriores al $20500 \mathrm{BP}$, hecho que, unido a la fecha del nivel II suprayacente (Ua-37959: $19675 \pm 220$; Altuna et al. 2011:37), sitúa con cierta seguridad al nivel III en el rango temporal del 20500 al 19500 BP. Su industria, muy vinculada aparentemente al Gravetiense (elementos de dorso, truncaduras y un número importante de buriles, entre ellos del tipo NoaiIles), lo asemejaría al nivel $\mathrm{V}$ de Amalda y, por extensión, a un momento final del Gravetiense.

Con fechas ligeramente más antiguas encontramos niveles como el 5a de Morín o el E de La Garma, que, con industrias caracterizadas por el utillaje de retoque abrupto (láminas de dorso en el primero y puntas de La Gravette en el segundo, a falta de datos cuantitativos precisos) parecen ajustarse bien al Gravetiense. El nivel D de Hornos de la Peña, por su parte, es más problemático, con industria poco diagnóstica y con posibles problemas estratigráficos asociados. Además, existen dudas acerca de la validez del proceso de muestreo de algunas de estas dataciones. Nos referimos, en concreto, a las dos fechas del nivel V de la cueva de Amalda, obtenidas a partir de un conjunto de varios fragmentos de hueso recogidos en lechos distintos. Esto podría explicar sus posibles valores anómalos.

El segundo rango modelado, relativo al comienzo de las primeras industrias solutrenses en el área cantábrica, se muestra en la Fig. 4.

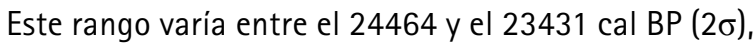
siendo la media $23926 \pm 268$ cal BP y la mediana 23914 cal BP. El límite inferior de la fase solutrense está determinado por la fechas de buena parte de los niveles de Las Caldas $(18,16,12$ y 9), el nivel $C$ de Hornos de la Peña, el 10 de La Riera, el Lmc de Antoliñako Koba, el 127 de El Mirón o el Vb/E de Cueto de la Mina. La filiación cultural de buena parte de estos niveles parece estar bien contrastada merced a la existencia de industria de retoque plano

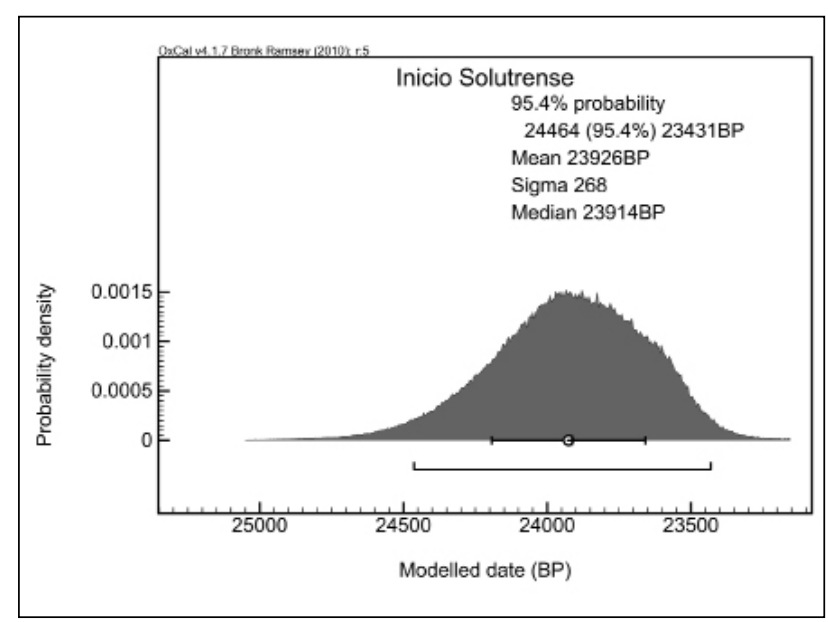

A Figura 4. Detalle del rango modelado del inicio del Solutrense en el área cantábrica. 


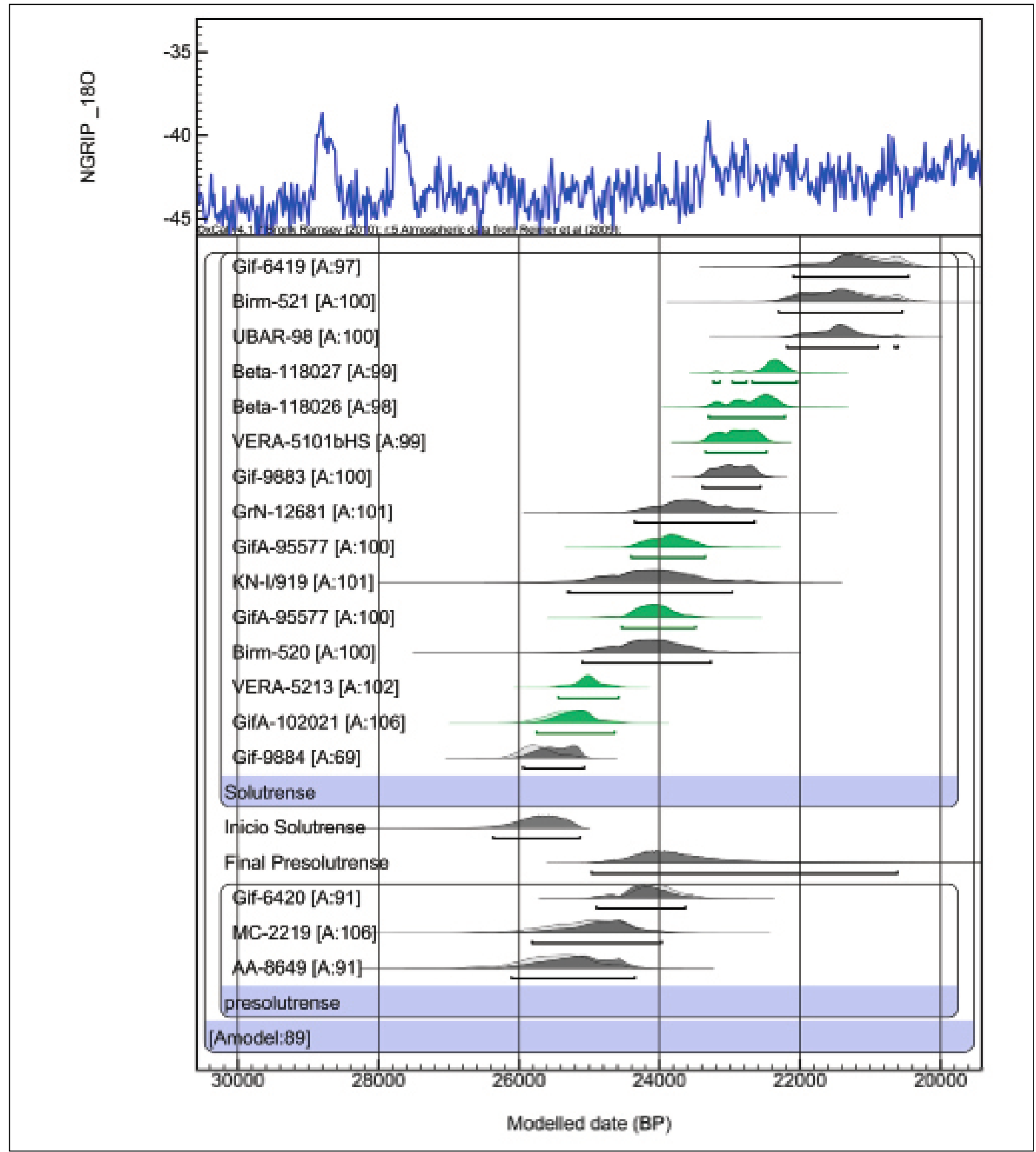

$\Delta$ FiguRA 5. Secuencia cronológica calibrada y modelada del área mediterránea. Las dataciones por AMS están coloreadas en verde. Las zonas de coloración más clara corresponden a los rangos calibrados y las más oscuras corresponden a los rangos modelados.

diagnóstica, tales como hojas de laurel (La Riera, Cueto de la Mina y Las Caldas), puntas de base cóncava (Antoliñako Koba y Las Caldas) y puntas de cara plana (Las Caldas). El nivel $\mathrm{C}$ de Hornos de la Peña, por el contrario, se presenta con más dudas. Su vinculación industrial con el Solutrense se basa en la existencia de un posible fragmento de punta de cara plana, dentro de un conjunto de efectivos muy limitados y que posee rasgos "arcaizantes" que lo relacio- narían con etapas tempranas del Solutrense (de la Rasilla y Straus 2004).

El resto de dataciones, no describen grandes problemas en relación al muestreo de estas dataciones o la posición e integridad estratigráfica de sus respectivos niveles, salvo en el caso de la fecha (Gak-6447) del nivel 10 de La Riera (y el mencionado estrato $\mathrm{C}$ de Hornos de la Peña). Straus et al. (1986) plantearon la existencia de posibles percolacio- 
nes, contaminaciones o dudas en los estándares de laboratorio (ya documentados por ejemplo en la datación BM-1739R de este mismo yacimiento) como explicación a la gran antigüedad de esta datación. Más recientemente esta datación ha sido considerada, de igual forma, inválida (Soto-Barreiro 2003), debido a una supuesta discordancia con su industria asociada (hojas de laurel).

\section{2 Área mediterránea}

La evidencia radiocarbónica del tránsito Gravetiense/ Solutrense disponible en el área mediterránea es la más desigual y restringida de las tres consideradas. La secuencia cronológica, compuesta por 19 dataciones (16 niveles arqueológicos de 12 yacimientos distintos), está fuertemente descompensada en términos crono-culturales, con tan solo tres disponibles para el final del Gravetiense (Tabla 2). Se trata, además, de fechas obtenidas por $\mathrm{C} 14$ convencional, entre los años 70 y 90 . Por el contrario, la fase solutrense cuenta con un total de 16 dataciones, 7 de ellas realizadas por AMS. Este desequilibrio también puede verse en la distribución geográfica de las fechas; las tres gravetienses provienen de yacimientos catalanes, habiendo una total ausencia de información cronológica sobre el último tramo de este periodo en el resto del área mediterránea. Las dataciones solutrenses, sin embargo, se encuentran bien diseminadas por toda la región.

La secuencia cronológica calibrada y modelada que hemos obtenido se observa en la Fig. 5.
Ésta posee, globalmente, un nivel de concordancia elevado $(A=91)$. Ello se debe a los altos valores de agreement que poseen buena parte de las dataciones que la componen $(A \approx 100)$, con cifras máximas de 106 y mínimas de 75 . Todas las fechas son, por tanto, aceptables de cara a la valoración de la serie.

El rango modelado del final del Gravetiense en el área mediterránea es el que se presenta en la Fig. 6.

Como es apreciable, se trata de un rango excesivamente dilatado, con valores comprendidos entre el 24978 y el 20872 cal BP (2б). La media resultante posee una desviación típica igualmente amplia, de $23472 \pm 1.258$ cal BP y una mediana de 23826 cal BP. Todo ello se debe al

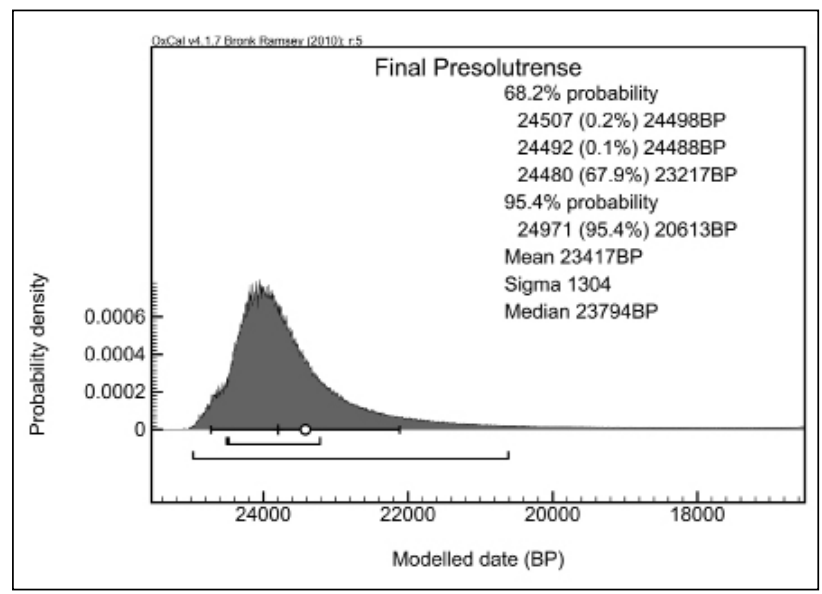

A Figura 6. Detalle del rango modelado del final del tecnocomplejo Gravetiense/Presolutrense en el área mediterránea.

\begin{tabular}{|c|c|c|c|c|c|c|c|c|c|c|}
\hline AR & YACIMIENTO & NIVEL & COD. LAB. & MT & MTD & FECHA BP & CALIB.BP $2 \sigma$ & MODEL.BP $2 \sigma$ & AD & REFERENCIA BIBLIOGRÁFICA \\
\hline M & BALMA DE LA GRIERA & III & AA-8649 & $\mathrm{H}$ & C & $21255 \pm 350$ & 26577-24461 & $26108-24347$ & G & Fullola et al. 1994 \\
\hline M & ROC DE LA MELCA & Único & MC-2219 & $\mathrm{H}$ & C & $20900 \pm 400$ & 26061-23969 & 25818-23973 & G & Soler 1979/80 \\
\hline M & L'ARBREDA & $\mathrm{E}$ & Gif-6420 & C & C & $20130 \pm 220$ & $24541-23415$ & 24894-23628 & G & Delibrias et al. 1987 \\
\hline$M$ & AMBROSIO & IV & Gif-9884 & $?$ & $\mathrm{C}$ & $21520 \pm 120$ & $26155-25190$ & 25937-25071 & $S$ & Ripoll et al. 2006 \\
\hline M & NERJA & 9 & GifA-102021 & C & AMS & $21140 \pm 190$ & $25907-24679$ & $25749-24637$ & $\mathrm{~S}$ & Aura et al. 2006 \\
\hline M & LA BOJA & $\mathrm{E}$ & VERA-5213 & C & C & $20980 \pm 100$ & $25464-24580$ & 25444-24582 & $\mathrm{S}$ & Zilhão et al. 2010 \\
\hline M & PARPALLÓ & $6^{\prime} 25-6^{\prime} 75$ & Birm-520 & $\mathrm{H}$ & C & $20170 \pm 380$ & $25096-23053$ & 25096-23267 & $\mathrm{S}$ & Shotton et al. 1975 \\
\hline M & AMBROSIO & II & GifA-95577* & $?$ & AMS & $20150 \pm 200$ & $24523-23482$ & $24535-23485$ & $S$ & Ripoll et al. 2006 \\
\hline M & MALLAETES & $5 a$ & KN-I/919 & $\mathrm{C}$ & $\mathrm{C}$ & $20140 \pm 460$ & $25195-22668$ & $25306-22963$ & $S$ & Fortea y Jordá 1976 \\
\hline M & AMBROSIO & II & GifA-95577* & ? & AMS & $19950 \pm 210$ & 24401-23333 & $24408-23350$ & $\mathrm{~S}$ & Ripoll et al. 2006 \\
\hline M & CHAVES & C1 & GrN-12681 & C & $\mathrm{C}$ & $19700 \pm 310$ & 24316-22614 & $24347-22648$ & $S$ & Baldellou y Utrilla 1985 \\
\hline M & AMBROSIO & II & GiF-9883 & $?$ & C & $19250 \pm 70$ & $23378-22549$ & $23385-22560$ & $\mathrm{~S}$ & Ripoll et al. 2006 \\
\hline M & FINCA DE DÑ MARTINA & $4-5$ & VERA-5101bHS & C & AMS & $19180 \pm 90$ & $23337-22466$ & $23347-22476$ & $S$ & Zilhão et al. 2010 \\
\hline M & CENDRES & XIII & Beta-118026 & C & AMS & $18920 \pm 180$ & 23288-22189 & $23295-22210$ & $S$ & Villaverde et al. 1999 \\
\hline M & CENDRES & XIII & Beta-118027 & $\mathrm{C}$ & AMS & $18750 \pm 130$ & $23227-22029$ & 23234-22042 & $S$ & Villaverde et al. 1999 \\
\hline M & NERJA & VIII-c & UBAR-98 & C & $\mathrm{C}$ & $17940 \pm 200$ & $22108-20558$ & 22185-20605 & $\mathrm{S}$ & Jordá et al. 1990 \\
\hline M & PARPALLÓ & $6-6 ' 25$ & Birm-521 & $\mathrm{H}$ & C & $17900 \pm 340$ & 22238-20437 & 22307-20547 & $S$ & Shotton et al. 1975 \\
\hline M & L'ARBREDA & Sol.Inf & Gif-6419 & $\mathrm{H}$ & C & $17720 \pm 290$ & 21959-20334 & 22092-20455 & $\mathrm{s}$ & Delibrias et al. 1987 \\
\hline
\end{tabular}

\ TABLa 2. Tabla de las dataciones seleccionadas para este estudio (2). Se hace referencia al área a la que pertenecen (AR), el yacimiento, el nivel, el código de laboratorio (COD. LAB), el material datado (MT: H para hueso, C para carbón y Co para concha) la metodología utilizada (MTD: AMS o C para C14 Convencional), datación BP (FECHA BP), datación calibrada (CALIB. BP 2б), modelación de la

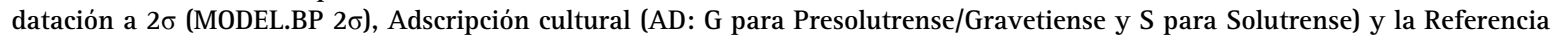
bibliográfica. 
bajo número de dataciones disponibles. A pesar de que este límite resulta muy poco determinante, tanto el rango modelado a $1 \sigma$, que oscila entre el 24507 y el 23260 cal BP, como la media y la mediana, indican que es el tramo más antiguo de este margen el que tiene mayor peso probabilistico.

Tecno-tipológicamente, es el nivel E de L'Arbreda el que se relaciona con más seguridad con el Gravetiense, debido a una industria dominada por el retoque abrupto (+70\%) y la abundancia de microgravettes y otros elementos de dorso (Soler y Maroto 1987). A pesar de que la muestra datada estaba formada por un conjunto de carbones, hecho que arroja ciertas dudas sobre la precisión de su resultado, esta datación (GIf-6420) ha sido considerada válida. Por el contrario, el nivel III de Balma de la Griera contiene un utillaje más reducido (solo 52 retocados) y menos diagnóstico, en el que no se han documentado piezas típicas (Fullola et al. 1994). Su secuencia estructural está dominada por el retoque simple con casi el $90 \%$ de los efectivos (casi en su totalidad denticulados y raspadores), siendo el resto elementos de retoque abrupto (puntas y láminas de dorso esencialmente). Por último, el único nivel de Roc de la Melca comparte características con los dos anteriores; hay en él una fuerte presencia del retoque simple ( $\pm 50 \%$ ), en forma de denticulados $y$, en menor medida, de raederas, así como una buena representación del retoque abrupto ( $\pm 33 \%$ ), principalmente (bi)truncaduras y utillaje de dorso y de dorso truncado (Soler 1980). Atribuido al Gravetiense, su industria no resulta determinante.

A este grupo cabría sumar, quizás, el nivel XIV de Les Cendres. Su contexto estratigráfico y su industria resultan problemáticos; según Villaverde y Román (2004), la existencia en él de un tipo gravetiense (punta de tipo Cendres) y otro solutrense (punta de cara plana) podría explicarse por la percolación de este último del nivel suprayacente, el XIII, hipótesis apoyada por la existencia de problemas de erosión a techo del estrato (Villaverde y Román 2004: 21). Por ello, creemos que la datación de este nivel (Beta-142282) debía ser desechada, dadas las dudas existentes en cuanto a su filiación e integridad estratigráfica.

En lo referido al inicio del Solutrense, el rango modelado generado es el que se observa en la Fig. 7.

Éste, debido al amplio número de dataciones disponibles, aporta una horquilla cronológica de gran precisión, entre el 26388 y el 25193 cal BP, con una media de 25771 \pm 316 cal BP y una mediana de 25741 cal BP. Los niveles con fechas más antiguas son el IV de Ambrosio, el 9 de Nerja y $E$ de La Boja. La datación del nivel IV de Ambrosio (Gif-9884) es, hasta el momento, la primera evidencia cronológica del Solutrense en el conjunto de la Península Ibérica. Asociada a ésta nos encontramos con buena parte del utillaje típico del Solutrense, tanto del mundo franco-cantábrico como del extra-cantábrico (hojas de laurel, puntas de cara plana, pun-

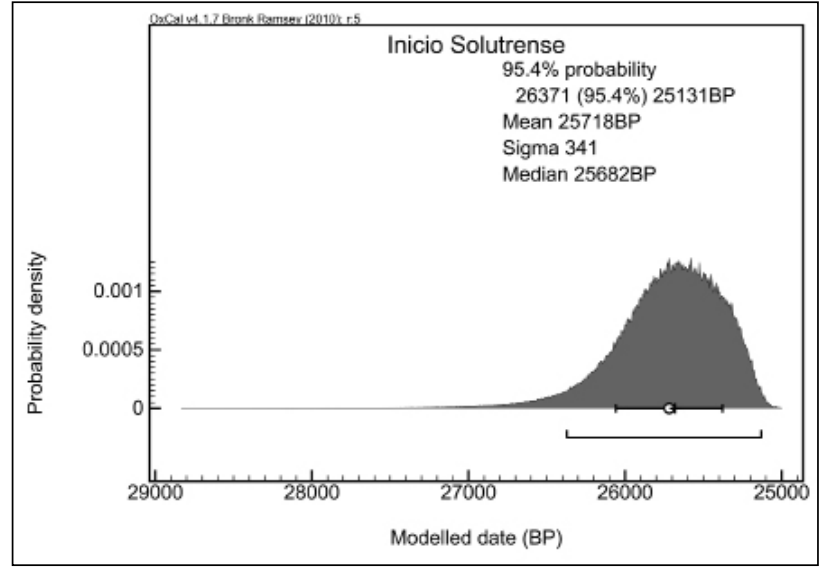

$\Delta$ Figura 7. Detalle del rango modelado del inicio del Solutrense en el área mediterránea.

tas de muesca de retoque abrupto y puntas de pedúnculo y aletas). En este horizonte conviven, de este modo, formas atribuidas tanto a etapas iniciales como a fases más plenas o avanzadas de la secuencia clásica del Solutrense. Por su parte, tanto el nivel 9 de Nerja como el E de La Boja han sido adscritos, gracias a la presencia de fragmentos de puntas de cara plana y otros elementos de retoque plano, al Solutrense inferior. En ambos se documenta, además, un claro descenso del retoque abrupto, muy presente en el Gravetiense. A esta fase inicial habría que vincular el tramo 6,25-6,75 $\mathrm{m}$ de la estratigrafía del Parpalló, teniendo en cuenta, por un lado, el aumento del retoque plano con respecto al horizonte Gravetiense infrayacente $y$, por otro, a la posible existencia de puntas de cara plana. Este supuesto fósil director del Solutrense inferior no vuelve a aparecer en la secuencia hasta el rango entre 23288 a 20437 cal BP, en los niveles XIII de Cendres, VIII-C de Nerja y 6-6,25 m de Parpalló, donde convive con hojas de laurel (en Nerja y Parpalló) y puntas de escotadura (en Cendres y Nerja). Este último está presente, así mismo, en L'Arbreda.

\section{3 Área atlántica}

El área atlántica es la última de las zonas seleccionadas y está compuesta por un buen número de dataciones (27) que están distribuidas en los 19 niveles de los 9 yacimientos seleccionados (Tabla 3). Aun estando repartidas en varios yacimientos, el de Vale Boi, con un total de 9 dataciones es el yacimiento "guía" de toda esta secuencia para ambas fases. Del total de dataciones, 9 corresponden a dataciones de niveles de la fase presolutrense y 18 a la fase solutrense. Ambas fases, pese a la obvia distribución desigual en el número de dataciones, están bien representadas, conformando grupos bien definidos en el ámbito industrial y cronológico. Respecto a la distribución geográfica, la mayoría de yacimientos arqueológicos seleccionados se sitúan entre la desembocadura del Tajo y del Mondego (8 de los 9 yacimientos). En la zona del Algarve encontramos otro yacimiento, Vale Boi. 


\begin{tabular}{|c|c|c|c|c|c|c|c|c|c|c|}
\hline AR & YACIMIENTO & NIVEL & COD. LAB. & MT & MTD & FECHA BP & CALIB.BP $2 \sigma$ & MODEL.BP 2 $\sigma$ & $A D$ & REFERENCIA BIBLIOGRÁFICA \\
\hline A & LAGAR VELHO & TP06 (us complex) & Wk-9256 & C & AMS & $22493 \pm 107$ & 27767-26702 & 27654-26240 & G & Pettitt et al. 2002 \\
\hline A & VALE BOI & 3 Vertente (Z27.8) & Wk-13686 & $\mathrm{H}$ & AMS & $22469 \pm 233$ & $27847-26296$ & 27617-26175 & G & Bicho 2008 \\
\hline$A$ & LAGAR VELHO & TP01 (us complex) & $0 \times A-10303$ & C & AMS & $22390 \pm 280$ & $27850-26188$ & $27584-26049$ & G & Pettitt et al. 2002 \\
\hline A & VALE BOI & D4 Abrg & Wk-26803 & Co & AMS & $21896 \pm 186$ & $26921-25736$ & $26821-25806$ & G & Bicho et al. 2010 \\
\hline A & VALE BOI & 3 Vertnt & Wk-16415 & Co & AMS & $21830 \pm 195$ & $26870-25569$ & $26787-25714$ & G & Bicho 2008 \\
\hline$A$ & BURACA ESCURA & $\mathrm{C} 2 \mathrm{a}$ & $0 \times A-5524$ & $\mathrm{H}$ & AMS & $21820 \pm 200$ & $26869-25529$ & $26790-25692$ & G & Aubry et al. 2001 \\
\hline A & TERRA DO MANUEL & $2 \mathrm{~s}$ & ETH-6038 & C & AMS & $21770 \pm 210$ & $26852-25411$ & $26764-25618$ & G & Zilhão 1997 \\
\hline A & LAPA DO ANECRIAL & 2 & $0 \times A-5526$ & C & AMS & $21560 \pm 220$ & 26620-25071 & 26659-25449 & G & Zilhão 1997 \\
\hline$A$ & LAGAR VELHO & TP06 & $0 \times A-8420$ & $\mathrm{C}$ & AMS & $21180 \pm 240$ & $26000-24593$ & $26540-25153$ & G & Pettitt et al. 2002 \\
\hline A & VALE BOI & C4 Abrg & Wk-26800 & $\mathrm{C}$ & AMS & $20620 \pm 160$ & $25045-24196$ & 24941-24144 & $S$ & Bicho et al. 2010 \\
\hline A & VALE BOI & D2 Abrg & Wk-26802 & C & AMS & $20570 \pm 158$ & $25020-24119$ & $24909-24043$ & $\mathrm{~S}$ & Bicho et al. 2010 \\
\hline$A$ & CALDEIRAO & $\mathrm{H}$ & 0xA-2511 & $\mathrm{H}$ & AMS & $20530 \pm 270$ & $25167-23823$ & $24913-23862$ & $S$ & Zilhão 1997 \\
\hline A & CALDEIRAO & $\mathrm{Fa}$ & 0xA-1938 & $\mathrm{H}$ & AMS & $20400 \pm 270$ & $25036-23710$ & $24874-23742$ & $S$ & Zilhão 1997 \\
\hline$A$ & VALE ALMOINHA & III & ICEN-71 & $\mathrm{C}$ & $\mathrm{C}$ & $20380 \pm 150$ & $24809-23885$ & $24722-23887$ & $S$ & Zilhão 1997 \\
\hline$A$ & VALE BOI & C1 Abrg & Wk-17840 & C & AMS & $20340 \pm 160$ & $24786-23845$ & 24699-23849 & $S$ & Bicho 2008 \\
\hline$A$ & SALEMAS & II & ICEN-376 & $\mathrm{H}$ & C & $20250 \pm 320$ & $24986-23436$ & $24809-23471$ & $S$ & Zilhão 1997 \\
\hline A & LAGAR VELHO & 9 & $0 \times A-8419$ & C & AMS & $20200 \pm 180$ & $24539-23552$ & $24535-23631$ & $S$ & Zilhão 1997 \\
\hline$A$ & VALE ALMOINHA & III & $0 \times A-5676$ & $\mathrm{C}$ & AMS & $19940 \pm 180$ & $24340-23364$ & $24344-23378$ & $S$ & Zilhão 1997 \\
\hline$A$ & CALDEIRAO & $\mathrm{H}$ & 0xA-1939 & $\mathrm{H}$ & AMS & $19000 \pm 260$ & $23442-22127$ & $23459-22168$ & $S$ & Zilhão 1997 \\
\hline$A$ & VALE BOI & B6 & Wk-24763 & $\mathrm{C}$ & AMS & $19533 \pm 92$ & $23720-22684$ & $23735-22694$ & $S$ & Bicho 2008 \\
\hline$A$ & SALEMAS & VS & ICEN-385 & $?$ & $C$ & $19220 \pm 300$ & $23715-22274$ & $23750-22305$ & $S$ & Zilhão 1997 \\
\hline A & VALE BOI & $2 \mathrm{SIp}$ & Wk-24765 & Co & AMS & $18859 \pm 90$ & $23233-22191$ & $23244-22200$ & $S$ & Bicho 2008 \\
\hline$A$ & CALDEIRAO & Fc & $0 \times A-2510$ & $\mathrm{H}$ & AMS & $18840 \pm 200$ & $23305-22040$ & $23302-22082$ & $S$ & Zilhão 1997 \\
\hline A & VALE BOI & $2 \mathrm{SIp}$ & Wk-12130 & $\mathrm{H}$ & AMS & $18410 \pm 165$ & $22357-21505$ & $22377-21526$ & $\mathrm{~s}$ & Bicho 2008 \\
\hline A & BURACA GRANDE & Cnjnt 9 & Gif-9502 & $\mathrm{H}$ & C & $17850 \pm 200$ & 21927-20518 & 22078-20580 & $\mathrm{S}$ & Zilhão 1997 \\
\hline A & SALEMAS & VS & ICEN-367 & $?$ & $C$ & $17770 \pm 420$ & $22280-20222$ & 22399-20447 & $\mathrm{S}$ & Zilhão 1997 \\
\hline$A$ & VALE BOI & $2 \mathrm{SIp}$ & Wk-12131 & $\mathrm{H}$ & AMS & $17634 \pm 110$ & $21405-20518$ & 21446-20566 & $S$ & Bicho 2008 \\
\hline
\end{tabular}

\ TABLA 3. Tabla de las dataciones seleccionadas para este estudio (3). Se hace referencia al área a la que pertenecen (AR), el yacimiento, el nivel, el código de laboratorio (COD.LAB), el material datado (MT: H para hueso, C para carbón y Co para concha) la metodología utilizada (MTD: AMS o C para C14 Convencional), datación BP (FECHA BP), datación calibrada (CALIB. BP 2б), modelación de la datación a $2 \sigma$ (MODEL.BP $2 \sigma$ ), Adscripción cultural (AD: G para Presolutrense/Gravetiense y S para Solutrense) y la Referencia bibliográfica.

Respecto a la metodología subyacente, en la mayoría de las dataciones se observa la utilización de la técnica del AMS (22 AMS contra 5 convencionales), una metodología que, como dijimos previamente, ofrece una mayor fiabilidad. Los únicos yacimientos datados y que hayan cumplido los criterios de selección de fechas de C14 convencional son Salemas, Buraca Grande y Vale Almoinha, yacimientos que, por otro lado, tienen dataciones realizadas por AMS. Un claro ejemplo de la expansión de esta técnica lo constituye la fase presolutrense, constituida toda ella por dataciones realizadas mediante la técnica del AMS. La extensión de esta metodología se debe a que la mayoria de las investigaciones se han desarrollado en este territorio en los últimas dos décadas, coincidiendo con la extensión de este método.

La secuencia de fechas calibradas y modeladas del área atlántica aparece reflejada en la Fig. 8.

Las características, que definen este marco cronológico son la precisión y homogeneidad. Esto se ve reflejado en un indice de agreement de la secuencia realmente alto (Amodel=97). Individualmente, estos valores son altos $(A \approx 100)$, a excepción de la fecha situada en el límite superior de la fase Presolutrense (0xA-8420), correspondiente al nivel TD-06 de
Lagar Velho, con un nivel de concordancia bajo, $(A=60)$. Por este motivo, esta datación habrá que valorarla con ciertas reservas de cara a la discusión.

Centrándonos en los límites de las fases, el primero a analizar es la fase presolutrense. El final de la misma se sitúa a dos sigmas entre el 26210-24925 cal BP, con una media de 25638 \pm 326 cal BP y una mediana de 25681 cal BP. El rango cronológico modelado que define este límite está expuesto en la Fig. 9.

Este rango está bien definido a través de una reciente serie de dataciones, compuesto por 6 fechas. Estas son las dataciones del nivel TP06 de Lagar Velho (0xA-8420), el nivel 2 de Lapa do Anecrial (0xA-5526), el nivel 2s de Terra do Manuel (ETH-6038), el nivel C2a de Buraca Escura (0xA-5524) y los niveles 3 Vertente y D4 Abrigo de Vale Boi (Wk-16415 y Wk-26803). La datación de Lagar Velho, antes mencionada, es claramente más reciente que las otras cinco, y debe ser puesta en cuarentena, más aun teniendo en cuenta que está asociada a un contexto funerario. Éste, es escasamente representativo desde el punto de vista tipológico, puesto que posee solo 15 tipos retocados poco caracteristicos de los complejos que en este trabajo analizamos (Zilhão y Trinkaus 2002). 


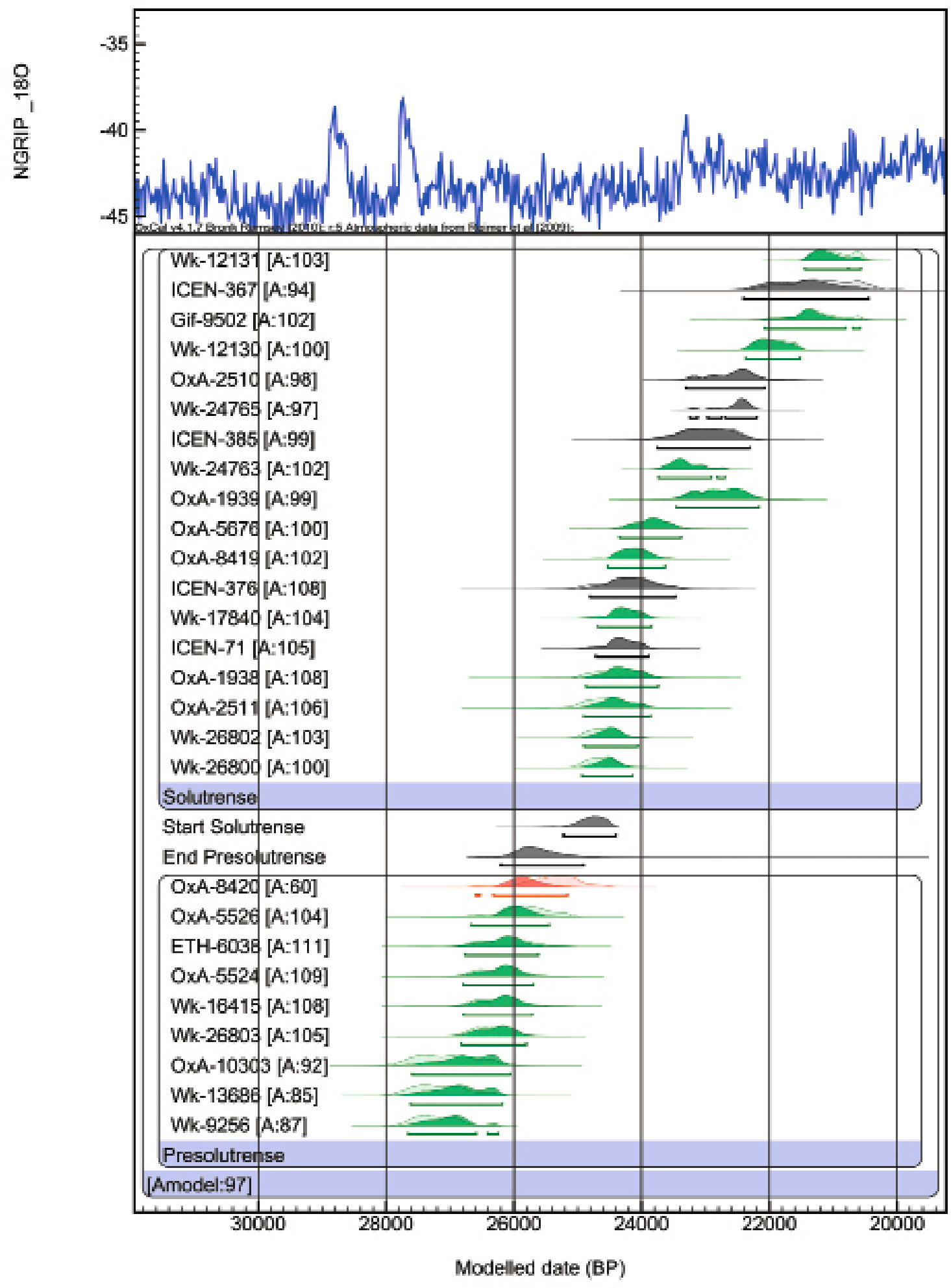

$\Delta$ FiguRa 8. Secuencia cronológica calibrada del área atlántica. Las dataciones por AMS están coloreadas en verde y las de bajo Agreement $(\mathrm{A} \leq 60)$ en rojo. Las zonas de coloración más clara corresponden a los rangos calibrados y las más oscuras corresponden a los rangos modelados.

El resto de dataciones que componen este límite final de la fase presolutrense poseen unos índices de concordancia más elevados, todos en torno a 100, y además datan contextos mejor definidos en el plano industrial y acordes con la fase establecida como Presolutrense, aunque no así en la denominación realizada por los autores que definen las industrias de los niveles. Así, la referente a Lapa do Anecrial (Zilhão 1997) es definida como Auriñaciense V, la industria 


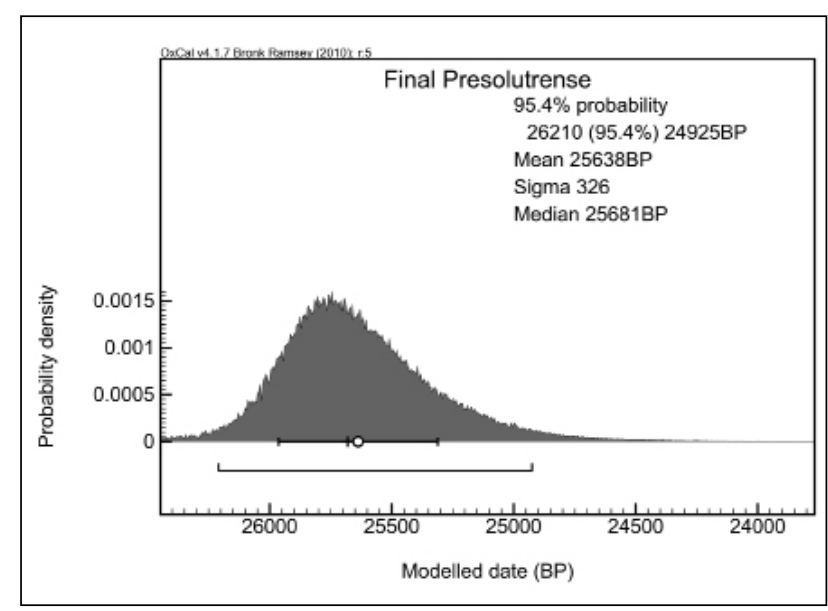

A Figura 9. Detalle del rango modelado del final del tecno-complejo Gravetiense/Presolutrense en el área atlántica.

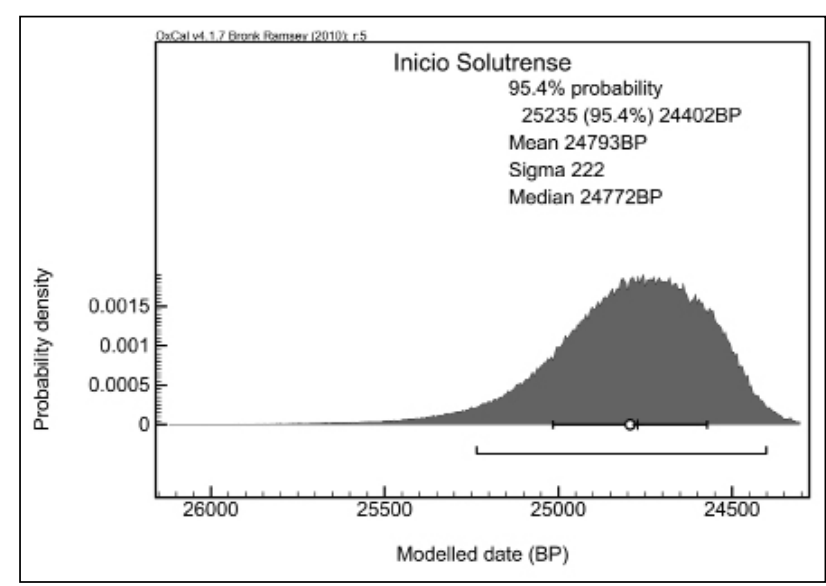

A Figura 10. Detalle del rango modelado del inicio del Solutrense en el área atlántica.

de Terra do Manuel (Zilhão 1997) como Perigordiense VII o Proto-Magdaleniense con Puntas do Vale do Comprido y la industria existente en Buraca Escura (Zilhão 1997) como Gravetiense con las puntas ya citadas, una industria muy similar a la que encontramos en Vale Boi (Bicho 2008).

Respecto al segundo de los límites que intentamos aclarar, el inicio del Solutrense, en esta región parece darse entre el 25235 y el 24402 cal BP, con una media de $24793 \pm 222$ cal BP y una mediana de 24772 cal BP. Este rango cronológico se puede apreciar en la Fig. 10.

Los niveles datados que favorecen la creación de este limite inicial son las de los niveles C4 y D2 del Abrigo de Vale Boi (Wk-26800 y Wk-26802) y las de Caldeirão, niveles $\mathrm{H}$ y Fe (0xA-2511 y 0xA-1938). Estas dataciones tienen unos altos indices de agreement $(A \approx 100)$. La industria asociada a estos niveles es claramente Solutrense, definida por el retoque plano en puntas de diferentes morfologías. Entre las puntas de los niveles de Vale Boi encontramos puntas de pedúnculo y aletas, puntas de pedúnculo lateral, fragmentos de piezas bifaciales y esbozos de piezas bifaciales
(Cascalheira 2010). Entre las piezas de los niveles H y Fc, Zilhão describe puntas de cara plana y hojas de laurel (Zilhão 1997). El resto de dataciones que conforman esta fase parecen articularse a través de una larga serie de dataciones con altos índices de agreement.

\section{DISCUSIÓN}

\subsection{Los más recientes métodos de datación y pretratamiento. ¿Una opción o una necesidad?}

El desarrollo metodológico de la técnica del C14 ha revolucionado la visión de la Prehistoria, posibilitando la creación de cronologías ordenadas a través de una línea temporal, trabajo realizado desde su origen, hace ya más de medio siglo (Libby et al. 1949). Colin Renfrew (1986), con su obra original de 1973 Before Civilization, ya mostraba cómo este método modificó la cronología de la Prehistoria y muchas de las ideas asociadas a los rígidos esquemas clásicos de perspectiva evolucionista. Este método ha desarrollado multitud de mejoras que posibilitan una mayor precisión y fiabilidad de las dataciones. A nivel general, las más importantes fueron la creación de las curvas de calibración, herramienta que permite vincular, con cada vez mayor precisión, la edad radiocarbónica al ciclo calendárico-véase la primera y la última (Anderson y Libby 1951; Reimer et al. 2009)-. Otra mejora es el desarrollo de la técnica de AMS, que posibilita la extracción de material datable de pequeños fragmentos de hueso o carbón, favoreciendo la filiación individual entre muestra (individual) y datación (Linick et al. 1989). Además, sucesivos avances han mejorado paulatinamente las dataciones por C14, favoreciendo su precisión y fiabilidad.

Este continuo desarrollo metodológico ha propiciado la existencia de dataciones muy dispares. La introducción y extensión en la utilización de la técnica del AMS a partir de la década de los 90, ha sido el desarrollo metodológico que más disparidad ha generado al compararlas con fechas obtenidas por el método tradicional. Esto genera, en determinadas zonas y contextos, problemas de fiabilidad y falta de precisión que requieren una valoración individualizada de cada una de las dataciones.

Un claro ejemplo de esta disparidad de fechas provocada por este factor se observa en el Nivel II de la Cueva de Ambrosio (Fig. 11) (Ripoll et al. 2006). En este, las fechas de dos dataciones realizadas por $\mathrm{C} 14$ convencional tienen un rango de variación entre sus medias calibradas superior a 3.000 años. Por el contrario, las fechas de AMS, muestran una desviación inferior a 300 años, a priori, una muestra de su mayor precisión. Zonas como la cantábrica (20 de C14 convencional y 12 AMS) y la mediterránea (11 de C14 convencional y 7 de AMS) están especialmente influenciadas por 


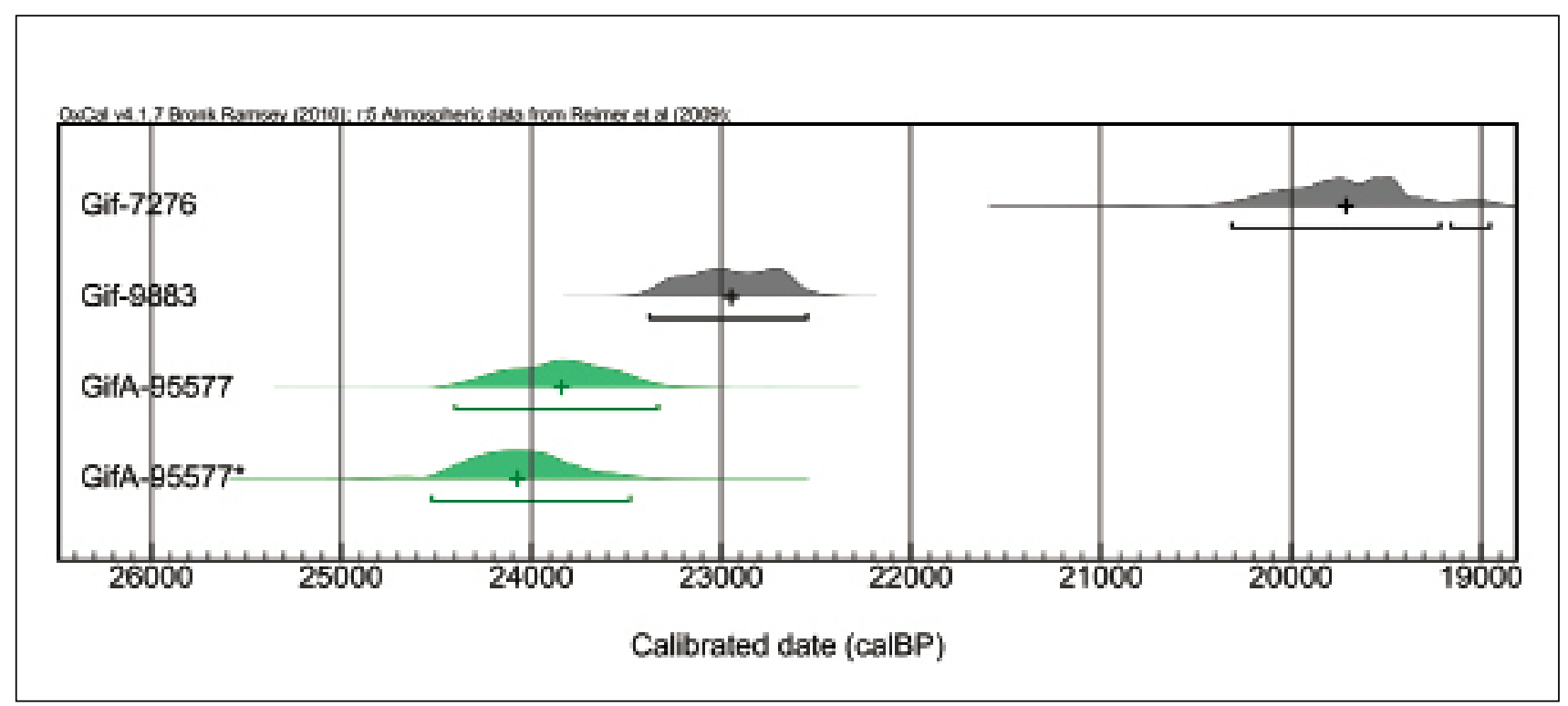

A FigURA 11. Gráfica comparativa entre dataciones obtenidas por C14 convencional y AMS (coloreadas en verde).

este desigual tratamiento, no así el área portuguesa, con la mayoría de dataciones realizadas a través del AMS (22 AMS y 5 de C14 convencional). La precisión de las dataciones ha aumentado gracias a otros avances técnicos, menos extendidos y con menor impacto como la utilización sistemática de estándares internacionales, utilización de muestreos de mayor rigor o métodos de limpieza de los materiales.

A lo largo de los últimos años, el desarrollo y extensión de avances metodológicos han sido muy importantes, principalmente en las curvas de calibración, los métodos de tratamiento de las propias dataciones y los métodos de pretratamiento de muestras, llegando a ser considerados por Bronk Ramsey (2008) como una auténtica revolución. Los últimos están compuestos principalmente por el Aboxsc (Bird et al. 1999) para el tratamiento de carbones y la Ultrafiltración (Law y Hedges 1989) para materiales óseos. Estos métodos consiguen eliminar la contaminación que haya podido sufrir la muestra por la acción de procesos post-deposicionales, haciendo una datación más precisa y en la mayoría de ocasiones más antigua. Un envejecimiento que se acentúa en muestras de mayor edad y que para este periodo podría ser de 840 años (con $1 \%$ de carbono contaminante actual en la muestra), según estudios publicados por el Oxford Radiocarbon Accelerator Unit (Bronk Ramsey 2008). La utilización de estos avances en este periodo, creemos, sería capaz de precisar la problemática cronológica que aún persiste, modificando los esquemas clásicos y los aquí planteados, abriendo una nueva vía para la investigación. Otros periodos prehistóricos, quizá con mayor problemática cronológica, ya han sido modificados, como muestra uno de los casos más paradigmáticos, el tránsito del Paleolítico medio al superior (Higham 2011; Prieto 2012).

Por todo lo expuesto hasta el momento, necesidad de obtener una mayor precisión de los datos cronológicos y posibi- lidad metodológica, creemos necesaria la utilización de forma sistemática de la técnica del AMS, por su extensión, disponibilidad y precisión. El marco cronológico mostrado en el área atlántica es un claro ejemplo de cómo la utilización sistemática de esta técnica favorece la creación de marcos cronológicos más precisos. La utilización de métodos de pretratamiento exhaustivos (Abox-sc y Ultrafiltración), permitiría si cabe una mejor definición de este periodo, al menos en lo cronológico. Por tanto, consideramos una necesidad la utilización sistemática de la técnica del AMS y la introducción paulatina de estos nuevos métodos de pretratamiento ya enunciados.

\subsection{El final del Gravetiense y el comienzo del Solutrense en la Península Ibérica}

Como acabamos de ver, la transición entre el Gravetiense y el Solutrense tuvo ritmos y dinámicas muy variables en las distintas áreas geográficas. Si bien la evidencia radiocarbónica aporta información cronológica (e indirectamente geográfica) relevante en relación a este momento de cambio, especialmente tras su calibración y modelación bayesiana, esta no está exenta de ciertos problemas, siendo necesario realizar una serie de matizaciones y comentarios con respecto a los resultados obtenidos (Fig. 12).

Continuando con el orden seguido hasta ahora, comenzaremos con el área cantábrica. Las fechas del rango modelado del final de las industrias presolutrenses/gravetienses es el más reciente del conjunto de la Península. De esta manera, parece que es en esta región donde mayor pervivencia tuvieron estos tecno-complejos, especialmente en su zona más oriental. Sin embargo, son preceptivas una serie de puntualizaciones. Las dataciones del nivel V de Amalda, III de Aitzbitarte III y 1 de La Riera son, como ya hemos argumentado, problemáticas, siendo plausible que algunas 


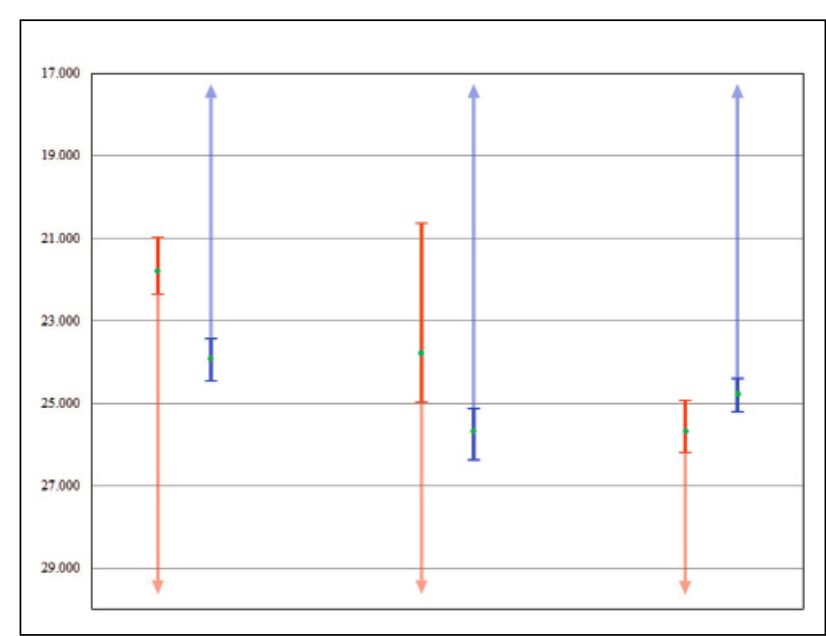

A Figura 12. Secuencia cronológica de las tres zonas a partir de cada una de las secuencias modeladas en cada área. De izquierda a derecha, área cantábrica, área mediterránea y área atlántica. En rojo la fase presolutrense y en azul la solutrense. Los rangos delimitados por las líneas perpendiculares son los rangos modelados de inicio y final de fase. Los puntos verdes son los valores de la mediana del rango modelado de apertura o cierre de fase. La cronología está en años calibrados.

de ellas resultaran inválidas. De ser así, el rango modelado estaría rejuvenecido, aunque en un grado imposible de determinar. Esto último se debe, principalmente, a la inexistencia de elementos de juicio adicionales (e. g. los porcentajes de rendimiento del colágeno o el ratio $\mathrm{C} / \mathrm{N}$ de las muestras datadas) que posibiliten determinar cuáles de estas fechas podrian ser anómalas.

No hay que descartar por completo que, en caso contrario, la perduración de estas industrias podría haberse prolongado hasta el 21000 cal BP. En este sentido, creemos que los niveles V de Amalda y III-II de Aitzbitarte III (y quizás el 1 de La Riera y el $D$ de Hornos de la Peña) pueden corresponder a un momento intermedio entre ambos periodos (aproximadamente entre el 23500 y el 21000 cal BP), en el que aún subsisten útiles de raigambre gravetiense y donde empiezan a eclosionar tipos de retoque plano, aunque aún bajo formas no diagnósticas.

Como ya hemos comentado, en el área cantábrica se observa una mayor perdurabilidad, en lo cronológico, de las industrias presolutrenses/gravetienses en comparación con el resto de áreas. La diferencia entre las medias de los respectivos rangos es de 1700 años entre las áreas cantábrica y mediterránea, y de casi 3900 años entre la cantábrica y la atlántica. Algunas dataciones comparables a este periodo en Francia son la Ly-2185: $18610 \pm 440$ BP (23445-21260 cal BP) de los niveles I/III de Le Flageolet I (Evin et al. 1985) o la GrN-1864: $18470 \pm 280$ BP (22900-21339 cal BP) del nivel 3 del Abri Pataud (Vogel y Waterbolk 1963).

En relación al rango modelado del inicio del Solutrense en el área cantábrica deben hacerse, de igual forma, las pertinentes aclaraciones. La validez de las tres dataciones más antiguas (Ua15318 de Las Caldas 15, BM-1882R de Hornos de la Peña D y
Gak-6447 de La Riera 10) resulta discutible, debido a las causas ya expuestas. Si aceptamos la posibilidad de una total o parcial invalidez de éstas, debería asumirse un probable envejecimiento de este límite, a un nivel, también en este caso, difícil de especificar. Sin embargo, parece bien atestiguada la presencia de utillaje foliáceo en torno al 24000-22500 cal BP en los niveles 16 y 12 de Las Caldas, horquilla, por otro lado, similar a la aportada por el rango modelado. La comparación del rango obtenido para esta área con el resto de los rangos de la Península lbérica muestra una más tardía aparición de las industrias solutrenses, de 1.800 años con respecto al área mediterránea y de 860 años con respecto al área atlántica. Las dataciones que muestran un rango cronológico similar en estas últimas áreas las encontramos en los niveles II de Ambrosio, 5a de Mallaetes y el nivel C1 de Chaves, así como en los niveles III de Vale Almoinha, el nivel $\mathrm{H}$ de Caldeirão y el nivel B6 de Vale Boi. En Francia, encontramos paralelos en las dataciones de 0xA-373: $20400 \pm 450$ BP (25663-23333 cal BP) del nivel 1 del Abri Pataud (Gowlett et al. 1987), GrN-4469: $20160 \pm 100$ BP (24420-23780 cal BP) del nivel 12a de Laugerie-Haute Ouest (Vogel y Waterbolk 1967), o Ly-799: $19710 \pm 400$ BP (24472-22475 cal BP) del nivel 7 de Baume d'Oullins (Evin et al. 1975).

En la segunda de las áreas, la mediterránea, se observa un esquema cronológico diferente del precedente. En cuanto al rango modelado del final del Gravetiense debe reiterarse que, pese a su gran amplitud, el tramo de mayor probabilidad es el que oscila entre el 24500 y el 23000 cal BP, haciendo improbable que las industrias gravetienses hubieran persistido más allá del 23000 cal BP. Los niveles datados que conforman este rango provienen de la zona más septentrional del área. Los paralelos peninsulares a estas fechas se encuentran en el nivel III de Aitzbitarte III (Ua-11147 y Ua-11149) y en el nivel 5 a de Cueva Morín (Si-953), dentro del área cantábrica. En el área atlántica no se encuentran paralelos, pues la distancia entre las medias de ambas fases es de 2.100 años, teniendo las industrias presolutrenses/gravetienses una mayor perdurabilidad en el área mediterránea. En Francia, encontramos varias dataciones contemporáneas a este rango: la Gif-8175: $19700 \pm 160$ BP (24032-22736 cal BP) del nivel 2D de la Grotte du Pape de Brassempouy (Buisson 1996), la Ly-2151: $19500 \pm 480$ BP (24479-22225 cal BP) del Perigordiense Va de Le Vigne-Brun (Evin et al. 1985).

Por su parte, el rango modelado del inicio del Solutrense en la región mediterránea es el más antiguo de los tres generados para la Península Ibérica, teniendo las fechas más antiguas en su zona más meridional. La fecha del nivel IV de Ambrosio, pese a tener un bajo índice de agreement, está considerada como válida, puesto que se constata en fechas similares la existencia de más niveles de este primer horizonte Solutrense con puntas de cara plana (Nerja 9, La Boja E y Parpalló 6,25-6,75 m.). El distanciamiento del inicio de esta fase con respecto al área cantábrica es de 1.800 años y de 1.000 años respecto al área atlántica. Los paralelos cro- 
nológicos de este rango en Francia son escasos, pudiendo citarse las siguientes dataciones: la 0xA-486: $22100 \pm 400$ BP (27863-25519 cal BP) del nivel III a-b de Combe Saunière (Gowlett et al. 1986), la Ly-847: $21650 \pm 800$ BP (2819224167 cal BP) del nivel E-F de Tete de Lion (Evin et al. 1985), o la MC-2449: $21600 \pm 70$ BP (26216-25487 cal BP) del nivel i/8 de Salpêtrière (Evin et al. 1983). Para la última área, la atlántica, se han obtenido rangos modelados de gran precisión. El relativo al final de las industrias gravetienses puede considerarse globalmente válido, a pesar del bajo valor de concordancia de la fecha 0xA-8420 de Lagar Velho TP06. Así lo atestiguan las fechas de los niveles Protosolutrenses de Vale Boi, Terra do Manuel y Buraca Escura y la del Auriñaciense V de Lapa do Anecrial, datados entre el 26800 y el 25000 cal BP. Como ya hemos comentado, esta horquilla es la más antigua de las obtenidas en el conjunto de la Península Ibérica. En Francia encontramos varias dataciones equivalentes a este rango, entre otras: la Ly-562: $21600 \pm 700 \mathrm{BP}$ (27930-24340 cal BP) del nivel 6 de Solutré (Evin et al. 1973),la GrN-1892: $21540 \pm 160$ BP (26232-25131 cal BP) del nivel 3 del Abri Pataud (Vogel y Waterbolk 1963), la Ly-565: $21500 \pm 700$ BP (27872-24234 cal BP) del nivel 39 de Le Blot (Evin et al. 1973), o la Ly-1607: $21190 \pm 920$ BP (28055-23385 cal BP) del nivel IV de Le Flageolet I (Evin et al. 1985).

El rango modelado del origen del Solutrense en esta área es el más preciso de todos los obtenidos, pudiendo considerarse sus valores como plenamente válidos. Como hemos visto, este límite es ligeramente más antiguo que el propio del área cantábrica y más reciente que el del área mediterránea. Con respecto a Francia, los niveles inferiores de Laugerie Haute Ouest (Solutrense inferior), aporta cuatro dataciones equivalentes a este rango: GrN-4446: 20810 \pm 230 BP (25541-24271 cal BP), GrN-4573: $20750 \pm 150$ BP (25127-24351 cal BP), GifA-100632: $20690 \pm 210$ BP (25257-24104 cal BP) y Ly-1175 (0xA) $20360 \pm 160$ (2481223861 cal BP) (Vogel y Waterbolk 1967; Roque et al. 2000).

Por último, deben hacerse ciertas consideraciones acerca de la fuerte variabilidad industrial documentada en ambas fases. Es en la fase solutrense donde creemos que esta es más relevante, puesto que se observa una realidad industrial que no concuerda con la secuencia clásica, vertebrada en función de los distintos fósiles directores. De este modo, se observa una reiterada presencia de tipos vinculados a momentos avanzados del Solutrense en fases cronológicas iniciales del mismo. Es el caso, por ejemplo, de los niveles IV y II de Ambrosio, (Ripoll 1988), el nivel C4 de Vale Boi (Cascalheira 2010) o el nivel 15 de Las Caldas (Corchón 1999), todos ellos con puntas de diversa morfología y en rangos cronológicos antiguos. Creemos por tanto en la necesidad de realizar en los próximos años una profunda revisión de la secuencia clásica, así como de incorporar a esta discusión la información disponible sobre procesos tafonómicos, paleoclimáticos y/o geoarqueológicos (Soto-Barreiro 2003; Aubry et al. 2011).

\section{CONCLUSIONES Y PERSPECTIVAS DE FUTURO}

Las principales conclusiones obtenidas en este trabajo son las siguientes:

1. La finalización de la fase presolutrense/gravetiense en el área cantábrica es la más reciente de la Península lbérica, con un rango modelado que oscila entre el 22363 y el 20965 cal BP. En el área mediterránea, estos tecno-complejos perviven hasta el rango de 24507-23260 cal BP y, en el área atlántica, esta fase concluye entre el 26210 y el 24925 cal BP, el rango más antiguo en el conjunto de la Península.

2. Las primeras evidencias solutrenses se documentan en el área mediterránea, en el rango 26388-25193 cal BP. El rango obtenido en el área atlántica es ligeramente más reciente, con valores que oscilan entre el 25235 y el 24402 cal BP. La aparición más tardía de industrias solutrenses en la Península lbérica es documenta en el área cantábrica, en el rango modelado de 24464 al 23431 cal BP.

3. En ambas fases de estudio se documenta una gran variabilidad industrial, especialmente relevante en el caso de la fase solutrense. Lo temprano de la aparición, en las tres áreas estudiadas, de útiles foliáceos asociados clásicamente a fases plenas o avanzadas del solutrense, evidencia la necesidad de una profunda revisión de los esquemas clásicos.

4. En el estado actual de la investigación, el método radiocarbónico sufre ciertas limitaciones para resolver las problemáticas propuestas. Estas, no tienen que ver con el desarrollo del método radiocarbónico, si no con su aplicación en esta cronología. En este sentido, consideramos importante el uso sistemático de los más recientes métodos de datación (AMS) y pretratamiento de muestras (Abox-sc y Ultrafiltración).

\section{AGRADECIMIENTOS}

Los autores de este artículo son beneficiarios del Programa de Formación de Personal Investigador del Dpto. de Educación, Universidades e Investigación del Gobierno Vasco (RBFI-2012-236) (BFI-2012-121). Además, nos gustaría agradecer a Francisco Javier Santos la ayuda prestada, a nuestros compañeros de laboratorio Maite Iris Garcia, Naroa García, Blanca Ochoa, Arantzazu Pérez y Aitor Sánchez por sus aportes y correcciones al artículo y finalmente al Dr. Álvaro Arrizabalaga por sus consejos. • 


\section{BIBLIOGRAFÍA}

AgUIRRE, M. 2003: "El yacimiento de Antoliñako koba (Gautegiz-Arteaga, Bizkaia): secuencia estratigráfica y dinámica industrial. Avance de las campañas de excavación 1995-2000". Illunzar 4: 13-38.

Alcaraz Castaño, M. 2007: "El Ateriense del Norte de África y el Solutrense peninsular: ¿contactos transgibraltareños en el Pleistoceno Superior?". Munibe 58: 101-126.

AltunA, J. 1972: "Fauna de mamíferos de los yacimientos prehistóricos de Guipuzkoa". Munibe 24: 14-64.

AltunA, J., MarieZkURRenA, K. y Ríos, J. (eds.) 2011: Ocupaciones humanas en Aitzbitarte III (País Vasco) 33.600-18.400 BP (zona de entrada a la cueva) (Vol. 5). Gobierno Vasco. Vitoria-Gasteiz.

AltunA, J., Merino, J. M. y Areso, P. 1984: El yacimiento prehistórico de la cueva de Ekain (Deba, Guipúzcoa). Sociedad de Estudios Vascos con la colaboración de Sociedad de Ciencias Aranzadi. Donostia.

ANDERSON, E. y LIBBY, W. 1951: "World-wide distribution of natural radiocarbon". Physical Review 81 (1): 64-69.

Arias, P., Ontañón, R., Armendáriz, A. y Pereda, E. 2003: "Zona Arqueológica de La Garma (Ribamontán al Monte): La Garma A, cuevas sepulcrales y castro del Alto de la Garma". En P. Arias, R. Ontañon, C. Garcia-Moncó y L. C. Teira Mayolini (eds.): III Congreso del Neolítico en la Península Ibérica (Santander, 5-8 de octubre de 2003). Libro Guía de la Excursión, Preactas. Servicio de Publicaciones, Universidad de Cantabria. Santander: 43-57.

ArRizabalaga, A. 1995: "La industria lítica del Paleolítico Superior Inicial en el Oriente Cantábrico". Tesis Doctoral inédita. Universidad del País Vasco. Vitoria-Gasteiz.

Aubry, T., Brugal, J., Chauvière, F., Figueral, I., Moura, M. y Plisson, H. 2001: "Modalités droccupations au Paléolithique supérieur dans la grotte de Buraca Escura (Redinha, Pombal, Portugal)". Revista Portuguesa de Arqueologia 4 (2): 19-46.

Aubry, T., Dimuccio, L. A., Almeida, M., Neves, M. J., Angeluccl, D. E. y CUNHA, L. 2011: "Palaeoenvironmental forcing during the MiddleUpper Palaeolithic transition in central-western Portugal". Quaternary Research 75: 66-79.

AurA, J., JORDÁ, J. F. y ForTEA, J. 2006: "La cueva de Nerja (Málaga, España) y los inicios del Solutrense en Andalucia". Zephyrvs LIX: 6788.

BALdellou, V. y UtRILla, P. 1985: "Nuevas dataciones de Radiocarbono de la Prehistoria oscense". Trabajos de Prehistoria 42: 83-95.

BALDEÓN, A. 1990: "Las industrias de los niveles paleolíticos". En J. Altuna, A. Baldeón y K. Mariezkurrena (eds.): La Cueva de Amalda (Zestoa, País Vasco). Ocupaciones Paleolíticas y Pospaleolíticas. Fundación José Miguel Barandiarán. San Sebastián: 63-115.

BıcHo, N. 2008: "Historia de dois mares: ecologia do Paleolítico Superior em Vale Boi". Relatório anual de 2008. Universidade do Algarve. Faro.

Bicho, N., Manne, T., Cascalheira, J., Mendonça, C., Évora, M., Gibaja, J. y Pereira, T. 2010: "O Paleolitico superior do sudoeste da Península Ibérica: o caso do Algarve". En X. Mangano (ed.): El Paleolítico superior peninsular. Novedades del siglo XXI. Monografies SERP 8. Universitat de Barcelona. Barcelona: 219-238.

Bird, M., Ayliff, L., Fifield, L., Turney, C., Cresswell, R., Barrows, T. y David, B. 1999: "Radiocarbon dating of "old" charcoal using a wet oxidation, stepped-comustion procedure ". Radiocarbon 41 (2): 127-140.

BOSSELIN, B. y DJINDJIAN, F. 1997: "L'Aurignacien tardif: un facies de Transition du Gravettien au Solutreen". Prehistoire Europeenne 10: 107-25.

Bowman, S., Ambers, J. y LeESE, M. 1990: "Re-evaluation of the British Museum Radiocarbon dates issued between 1980 and 1984". Radiocabon 32 (1): 59-79.

BRONK RAMSEY, C. 2008: "Radiocarbon dating: Revolution in Undestanding". Archaeometry 50 (2): 27.

- 2009a: "Bayesian analysis of radiocarbon dates". Radiocarbon 51: 337-360.
- 2009b: "Dealing with outliers and offsets in radiocarbon dating". Radiocarbon 51 (3): 1023-1045.

Cascalmeira, J. 2010: Tecnologia Solutrense do Abrigo de Vale Boi. Centro de Arqueologia da Universidade de Lisboa. Lisboa.

CORChÓN, M. S. 1999: "Solutrense y Magdaleniense del oeste de la Cornisa Cantábrica: Dataciones C14 (Calibradas) y marco cronológico". Zephyrvs LII: 3-32.

DeliBRIAS, G., Romain, O. y LE HASIF, G. 1987: "Datation par la méthode du carbone 14 du remplissage de la grotte de l'Arbreda". Cypsela VI: 133-135.

DJINDJIAN F., KosLOWSKI, J. y OTtE, M. 1999: Le paléolithique supérieur en Europe. Ed. Armand Colin. Paris.

EVIN, J., MARECHAL, J. y MARIEN, G. 1983: "Lyon natural Radiocarbon measurements IX". Radiocabon 25 (1): 57-128.

FORTEA, J. y JORDÁ, F. 1976: "La Cueva de Les Mallaetes y los problemas del Paleolítico superior del Mediterráneo español". Zephyrvs XXVIXXVII: 129-166.

Fullola, J. M., Bartorli, R., CebriÀ, A., BergadÀ, M. M., Farell, D. y Nadal, J. 1994: "El Paleolítico Superior de Catalunya: El Gravetiense de la Balma de la Griera (Calafell, Baix Penedès, Tarragona)". 1 'Congreso de Arqueología Peninsular. Est.IV.Porto: 35-47.

GonzÁlez EChegaray, J. y FreEman, L. 1978: Vida y muerte en Cueva Morín. Institución cultural de Cantabria. Diputación Provincial. Santander.

Higham, T. 2011: "European Middle and Upper Palaeolithic radiocarbon dates are often older than they look: problems with previous dates and some remedies". Antiquity 85: 235-249.

Hoyos, M. y DE LA RASILlA, M. 1994: "Dataciones 14C del Paleolítico superior del Abrigo de Cueto de la Mina (Posada de Llanes, Asturias)". Trabajos de Prehistoria 51 (2): 143-147.

JordÁ CerdÁ, F. 1954: "Gravetiense y Epigravetiense en la España mediterránea", Caesaraugusta. Publicaciones del Seminario de Arqueología y Numismática Aragonesa 4: 7-30.

JoRdÁ, J. F., AURA, J. E. y JoRdÁ, F. 1990: "El límite Pleistoceno-Holoceno en el yacimiento de la cueva de Nerja". Geogaceta 8: 202-204.

LAPLACE, G. 1962: "Solutréen et foyers solutréens". Munibe 14: 414-455.

LAW, I. A. y HEDGES, R. E. M. 1989: "A semi-automated bone pretreatment system and the pretreatment of older and contaminated samples". Radiocarbon 31 (3): 247-253.

Lerol-Gourhan, A. 1988: Dictionnaire de la Préhistoire. Presses Universitaires de France. Paris.

LIBBY, W., ANDERSON, E. y ARNOLD, J. 1949: "Age determination by radiocarbon content: Wold-wide assay of natural radiocarbon". Science 109: 227-228.

Linick, T., DAMON, P., DonAhue, D. y JuLl, A. 1989: "Accelerator mass spectrometry: the new revolution in radiocarbon dating". Quaternary International 1: 1-6.

Pettitt, P., Van Der Plicht, J., Bronk Ramsey, C., Monge, A. y Zilhão, J. 2002: "The radiocarbon chronology". En J. Zilhão y E. Trinkaus (eds.): Portrait of the Artist as a Child. Instituto Português de Arqueologia. Lisboa: 132-138.

Prieto, A. 2012: "El marco cronológico para la transición del Paleolítico medio al superior en Europa, a la luz de las novedades del método radiocarbónico". CKO, Estudios de Cuaternario, 2: 115-144.

De la Rasilla, M. y Llana, C. 1995: "Del Solutrense en la Península lbérica. El Solutrense en Portugal y los inicios del Solutrense". Trabalhos de Antropologia e Etnologia 35 (4): 89-103.

De LA RASILLA, M. y StRAUS, L. 2004: "El poblamiento en la región cantábrica en torno al último máximo glacial: Gravetiense y Solutrense". Kobie (Serie de Anejos): 209-242.

RENARD, C. 2010: Les premières expressions du Solutréen dans le SudOuest français: evolution technoéconomique des équipements lithiques au cours du Dernier Maximum Glaciaire. BAR International Series, 2070. Oxford.

- 2011: "Continuity or discontinuity in the Late Glacial Maximum of south-western Europe: the formation of the Solutrean in France". World Archaeology 43 (4): 726-743. 
ReNFREW, C. 1986: El alba de la civilización. Itsmo. Madrid.

RIPOLL, S. 1988: El Solutrense de la Cueva de Ambrosio (Almería, Spain) y su posición cronoestratigráfica en el Mediterráneo Occidental. BAR International Series, 462. 0xford.

Ripoll, S., Muñoz, F. J. y Fernández, J. L. 2006: "Nuevos datos para el arte rupestre paleolítico de la cueva de Ambrosio (Vélez Blanco, Almeria)". En J. Martínez y M. Hernández (Eds.): Congreso de Arte Rupestre Esquemático en la Península lbérica. Almeria: 573-588.

Reimer, P. J., Baillie, M. G., Bard, E., Bayliss, A., BeCK, J. W., BlackWell, P. G., Bronk Ramsey, C., Buck, C. E., BurR, G., Edwards, R. L, Friedrich, M., Grootes, P., Guilderson, T., Hajdas, I., Heaton, T. J., Hogg, A. G., Hughen, K. A., Kaiser, K. F., Kromer, B., Mccormac, E. G., Manning, S. W., Reimer, S. D., Richards, D. A., Southon, J., Talamo, S., Turney, C., Van Der Plicht, J. y WEYHENMEYER, C. E. 2009: "Intcal09 and Marine09 radiocarbon age calibration curves, 0-50 000 years cal BP". Radiocarbon 51 (3): 1111-1150.

Rouve, C., Guibert, P., Vartanian, E., Bechtel, F., Schvoerer, M., Oberlin, C., Evin, J., Mercier, N., Valladas, H., TeXier, J.-P., Rigaud, J.-PH., DelpeCH, F., Cleyet-Merle, J.-J., TuRQ, A. 2001: "Une expérience de croisement de datations TL/C14 sur la séquence solutréenne de Laugerie-Haute, Dordogne (A TL and $14 \mathrm{C}$ dating experiment at the Solutrean site of Laugerie Haute West; Dordogne, France)". En J. N. Barrandon, P. Guibert y V. Michel (eds.): Datation, Actes des XXI ${ }^{\circ}$ Rencontres Internationales d'Archéologie et d'Histoire d'Antibes, 19-21 Octobre 2000, APDCA: 217-23.

Shotron, F. W., WiLliams, R. E. G. y Johnson, A. S. 1975: "Birmingham University Radiocabon Dates IX". Radiocabon 17 (3): 255-275.

SмITH, P. 1966: Le solutréen en France. Imprimeries Delmas. Bordeaux.

Soler, N. 1979/80: "El jaciment prehistòric del Roc de la Melca i la seva cronologia. Sant Aniol de Finistres (Girona)". Annals de I'Institut d'Estudis Gironins. Homenaje a LI. Batlle: 43-58.

SOLER, N. y MAROTO, J. 1987: "Els nivells d'ocupació del Paleolitic superior a la cova de l'Arbreda (Serinyà, Girona)". Cypsela VI: 221-228.

Soto-BARReIRo, M. J. 2003: Cronología radiométrica, ecología y clima del Paleolítico cantábrico. Museo Nacional y Centro de Interpretación de Investigación de Altamira. Madrid.

Straus, L. G. 1983: El Solutrense Vasco-Cantábrico: Una Nueva Perspectiva. Centro de Investigación y Museo de Altamira. Ministerio de Cultura de España. Madrid.

Straus, L. 2001: "Solutrean". En P. Peregrine y M. Ember (eds.): Encyclopedia of Prehistory (Vol. 4.). Kluwer Academic/Plenum. New York: 238-250.
Straus, L. y Clark, G. 1986: La Riera Cave, Stone Age hunter-gatherer adaptations in northern Spain.. Arizona State University. Arizona.

Straus, L. y GonzÁlez, M. 2003: "El Mirón Cave and the C14 Chronology of Cantabrian Spain". Radiocabon 45 (1): 41-58.

Straus, L., GonzÁlez, M., GutiérRez, I. y IRiARTE, M. J. 2011: "Further Solutrean evidence in El Mirón Cave (Ramales de la Victoria, Cantabria)". Munibe 62: 117-133.

TIFFAGOM, M. 2005: "El Solutrense de facies ibérica o la cuestión de los contactos Trans-mediterráneos (Europa, África) en el Último Máximo Glaciar". En J. L. Sanchidrián y J. M. Fullola (eds.): IVSimposio de Prehistoria Cueva de Nerja. La Cuenca Mediterránea durante el Paleolítico Superior, 38.000-10.000 años: 60-77.

- 2006: De la pierre à l'homme: essai sur une paléoanthropologie solutréenne. Service de Préhistoire Université de Liège. Liège.

Villaverde, V., Martinez-Valle, E., Badal, E., Guillem, P. M., Garcia, R. y MenARgues, J. 1999: "El Paleolítico superior de la Cova de les Cendres (Teuladaa-Moraira). Datos proporcionados por el sondeo efectuado en los cuadros A/B 17". Archivo de Prehistoria Levantina XXVIII: 6-65.

VILLAVERDE, V. y RoMAN, D. 2004: "Avance al estudio de los niveles gravetienses de la Cova de les Cendres. Resultados de la excavación del sondeo (cuadros $A / B / C-17$ ) y su valoración en el contexto del Gravetiense Mediterráneo Ibérico". Archivo de Prehistoria Levantina XXV: 19-59.

ZııHÃo, J. 1997: El Paleolitico Superior da Estremadura portuguesa. Colibri. Lisboa.

ZILHÃO J., y AUBRY T. 1995: "La pointe de Vale Comprido et les origines du Solutréen". I'Anthropologie 100 (1): 129-146.

ZILHÃo, J. AUBRY, T. y ALMEIDA, F. 1999: "Un modèle technologique pour le passage du Gravettien au Solutréen dans le sud-ouest de l'Europe". En D. Sacchi (ed.): Les faciès leptolithiques du nord-ouest méditerranéen: milieux naturels et culturels. Actes du XXIVe Congrès Préhistorique de la France. Carcassonne, 26-30 septembre 1994. Société Préhistorique Française: 165-183.

Zillä̃o, J., Angeluccl, D., Badal, E., Lucena, A., Martín, I., Martinez, S., VILLAVERDE, V. y ZAPATA, J. 2010: "Dos abrigos del Paleolítico superior en Rambla Perea (Mula, Murcia)». En X. Mangano (ed.): El Paleolítico superior peninsular. Novedades del siglo XXI. Monografies SERP 8. Universitat de Barcelona. Barcelona: 137-148.

ZILHÃO, J. y TrinkAuS, E. (eds.) 2002: Portrait of the Artist as a Child. The Gravetian Human Skeleton from the Abrigo do Lagar Velho and its Archaeological Context. Instituto Português de Arqueologia. Lisboa. 